\title{
Private Sector
}

\section{Participation in}

\section{Federal Energy}

RDED Planning

A report prepared by the

Committee on Private Sector Participation

in Government Energy RD\&D Planning

Commission on Natural Resources National Research Council

\section{NOTICE}

This report was prepared as an account of work sponsored by the United States Govemment. Neither the United States nor the United States Department of Energy, nor any of their employees, nor any of their contsactors, subcontractors, or their employees, makes any warranty, express or implied, or assumes any legal liability of responsibility for the accuracy, completeress liability of responsibility for the accuracy, completeness process disclosed, or represents that its use would not iniringe privately owned rights. 


\section{DISCLAIMER}

Portions of this document may be illegible in electronic image products. Images are produced from the best available original document. 
COMMITTEE ON PRIVATE SECTOR PARTICIPATION

IN GOVERNMENT ENERGY RD\&D PLANNING

Martin Goland, Chairman

Southwest Research Institute

Arthur M. Bueche

General Electric Company

heodore L. Cairns

E. I. du Pont de Nemours and Company, Inc.

William D. Carey

American Association for the Advancement of science

Dayton $\mathrm{H}$. Clewell

Mobil Oil Corporation (retired)

Peter T. Flawn

University of Texas

Ralph E. Gomory

International Business Machines Corporation

Milton Harris

Consultant

Eric H. Reichl

CONOCO Coal Development Company

Louis H. Roddis, Jr.

Consulting Engineer

Abe Silverstein

Republic Steel Corporation

Joseph C. Swidler

Leva, Hawes, Symington, Martin, and oppenheimer Mason Willrich

The Rockefeller Foundation

\section{Staff}

Winfred E. Berg - Special Projects officer

George White - Executive Secretary

Martha L. Beard - Staff Secretary

Linda E. Jones - Staff Secretary 
The project that is the subject of this report was approved by the Governing Board of the National Research Council, whose members are drawn from the Councils of the National Academy of Sciences, the National Academy of Engineering, and the Institute of Medicine. The members of the Committee responsible for the report were chosen for their special competences and with regard for appropria balance.

This report has been reviewed by a group other than the authors according to procedures approved by a Report Review Committee consisting of members of the National Academy of Sciences, the National Academy of Engineering, and the Institute of Medicine.

This study was completed under Contract EY-76-C-02-2708013 with the Department of Energy in April, 1978.

International Standard Book Number 0-309-02783-7

Library of Congress Card Number 78-60538

\section{Available from}

Printing and Publishing office

National Academy of Sciences

2101 Constitution Avenue, N. W. Washington, D. C. 20418

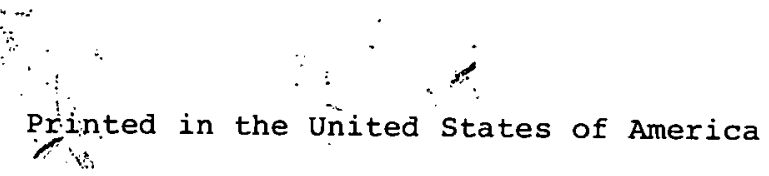


TABLE OF CONTENTS

PREFACE

vii

FRONTISPIECE

viii

EXECUTIVE SUMMARY

1

INTRODUCTION 4

CHAPTER I

THE GOVERNMENT ROLE IN ENERGY RD\&D

7

CHAPTER II

CHAPTER III THE ERDA (DOE)/PRIVATE SECTOR RD\&D PLANNING INTERFACE

Energy Advisory Committees

Determination. of Future Technology Requirements

Survey of Industrial In-House RD\&D 16

Activity

Enhancement of Management Expertise

CHAPTER IV

INDUSTRY PERCEPTIONS OF THE ERDA/PRIVATE SECTOR INTERFACE

Syn-fuels

Nuclear Power

Solar Power

CHAPTER V

LEGAL CONSTRAINTS TO DOE/PRIVATE SECTOR COOPERATION

The Conflict with the Government's 26 Effort at openness

Protection of Proprietary Information 28

The Protection of Patent Rights 29

Organizational Conflicts. of Interest 30

The Impact of Antitrust Considerations 32

Concluding Remarks 34

CHAPTER VII INSTABILITY AS A CONSTRAINT TO DOE/PRIVATE 35

SECTOR COOPERATION

CHAPTER VII THE RD\&D PLANNING PROCESS 38

The Energy RD\&D Advisory Board · 40

Executive Committee 41

Standing Advisory Committees 41

Ad Hoc Advisory Panels 42

Associate Members $\quad 42$

CHAPTER VIII CONCLUSIONS AND RECOMMENDATIONS 44

APPENDIX AN ANALYSIS OF FIVE LEGAL PROBLEMS IN

STRUCTURING PRIVATE SECTOR

PARTICIPATION IN JOINT RD\&D PLANNING 


\section{DISCLAIMER}

This report was prepared as an account of work sponsored by an agency of the United States Government. Neither the United States Government nor any agency Thereof, nor any of their employees, makes any warranty, express or implied, or assumes any legal liability or responsibility for the accuracy, completeness, or usefulness of any information, apparatus, product, or process disclosed, or represents that its use would not infringe privately owned rights. Reference herein to any specific commercial product, process, or service by trade name, trademark, manufacturer, or otherwise does not necessarily constitute or imply its endorsement, recommendation, or favoring by the United States Government or any agency thereof. The views and opinions of authors expressed herein do not necessarily state or reflect those of the United States Government or any agency thereof. 


\section{PREFACE}

The primary objective of the present study, as defined in the National Research Council's original proposal to the Energy Research and Development Administration (ERDA) in June 1976, was to recommend an institutional mechanism. to facilitate private sector participation in government planning of energy RDED programs. Between the time the proposal was made and the initial meeting of the committee in March 1977, the new Administration had indicated plans. previewed in President Carter's report to the Congress in January 1977. "The Organization of Federal Energy

Functions," to make major changes in the organization of the federal energy activities and responsibilities. To keep the study relevant in the new framework, the committee enlarged the scope and changed the primary focus of the study from the relatively narrow limits of original assignment to include the more complex question of government-industry relationships as they may affect the participatory planning process. The changes in federal energy organization included in recent "Department of Energy Organization Act" (42 USC 7101) and discussed in the study report. confirmed that this shift in approach was necessary.

The Committee recognizes that several study recommendations touch on very substantial legal issues. The perspective taken by the committee in making these recormendations is that these issues present problems to the participatory energy RDED planning process and must be addressed. The committee does not presume that it has made an analysis of sufficient depth and scope to design solutions to these problems, which will require further analysis in depth by legal and regulatory experts. 
"Energy is a pervasive and highly interrelated subject involving complex interactions between public and private sectors and among the numerous federal energy programs. The private sector plays the predominant role in meeting our energy requirements by providing the needed initiative, capital investment, know-how and Zabor."

- President Carter's Report to the Congress January, 1977, on "The Organization of Federal Energy Functions." 


\section{EXECUTIVE SUMMARY}

Insuring the energy future of our nation involves both the private sector and the federal government. working in cooperation with state and local authorities. While reserving for itself certain options such as hydroelectric power from federal water projects, the government should establish a sound national energy policy that takes full advantage of available and emerging energy options. and cooperate with and supplement the efforts of the energy industry to make certain that our national energy needs are met. The government should include in this responsibility the sponsorship of a strong research and development program to develop new technological options. The delivery of energy, and the commercialization of new technologies are primarily private sector responsibilities. In the words of President Carter, "the private sector plays the predominant role in meeting our energy requirements by providing the needed initiative, capital investment, know-how and labor."

This study was commissioned by the Energy Research and Development Administration (ERDA) (now Department of Energy [DOE]) to appraise the effectiveness of the private sector/government planning interface, specifically with respect to their cooperative efforts to introduce new energy options for the future. The principal objective of the study is to recommend ways in which joint planning between industry and government can be made more effective in the areas of research, development, and demonstration projects (RDED). Close coordination is essential if there is to be an effective relationship between DOE technological

initiatives and private sector capabilities and needs, and if the technology is to be moved rapidly from the RDED stages to practical application by industry.

Based on its studies, the Committee concludes that substantial improvement is needed. in DOE/private sector interaction at both the planning and the program implementation levels. However, before this can be accomplished, a number of obstacles must be overcome. significant legal constraints deter effective participation by representatives of the private sector in DOE planning activities. Some are imposed by legislation. others arise largely from uncertainties and restrictive interpretation of 
provisions contained in current laws and regulations. The combined effect of these constraints is to reduce, or even eliminate, the opportunity for DOE to obtain needed advice from experts in the private sector. or to develop programs in such a way that they lend themselves to early commercialization of research results.

Among the legal disincentives are those derived from provisions of the Freedom of Information Act, the Government in the Sunshine Act, the Federal Advisory Committee Act, anc the various laws relating to antitrust activities. The ability to protect proprietary data and trade secrets when such information is supplied to the government poses further complications. Issues relating to patent protection and program management practices also cloud the achievement of effective DOE/private sector collaboration.

While these laws provide the public protection against various abuses and should not be made less effective, the Committee believes that many of the legal constraints can be overcome if more definitive guidelines are established governing participation of experts from the private sector in DOE planning. Current laws and regulations should be reexamined to insure that they recognize the responsibilities and essential participation of the business community as a member of an effective energy partnership, while at the same time continuing to safeguard public interests and values with which the goverment is rightly concerned. The Secretary of Energy, in consultation with the Department of Justice, is urged to give early attention to the need for such a reconciliation.

The Committee also concludes that DOE would benefit from the estabiishment of a formal advisory Board reporting to the secretary of Energy, with membership including experts with backgrounds in industry, academia, and non-profit institutions. This Energy Research, Development, and Demonstration Advisory Board, along with its associated Committees, would give advice on policy and specific technical matters. similar advi sory mechanisms are in use by other government agencies, including the Departments of Defense, Transportation, Commerce, NASA, etc... and have proven their worth. The committee recommends the early establishment of the Advisory Board by the secretary. At the same time, the Committee cautions that the degree of effectiveness of this or any other advisory body will depen on the legal constraints on the membership.

Finally, the Committee wishes to emphasize the importance of arriving at a relatively stable national energy plan in order to make it possible for DOE to conduct a responsive energy RDED program. By their very nature, most emerging energy options require mahy years for the 
transition from the research to the utilization stage, and without reasonable program stability the private sector is hesitant to join with DOE in the commitment of the necessary and substantial resources. 


\section{CHAPTER I}

\section{INTRODOCTION}

Securing the energy future of the United States requires a cooperative partnership between the federal government and the private sector energy industry-3

The keynote to this theme was stated by President Carter in his Report to the Congress in January 1977 on The Organization of the Federal Energy Functions (frontispiece). secretary Schlesinger in his testimony before the committee on science and Technology of the House of Representatives on January 25, 1978, as he presented the Department of Energy's fiscal year 1979 energy program, stated:

"In developing new technologies, the traditional concept of RDED is not sufficient. The purpose of the energy research and development now must be aimed squarely at commercializing technologies at the earliest possible point. We must establish a set of priorities and likely energy supply pay-offs from each technology that is being pursued and move those technologies from the laboratory to the market place at the earliest point which is prudent."

The Department of Energy (DOE), formally established on October 1, 1977, brought together into one cabinet-level department. the bulk of the energy-related programs and offices of the federal government. DOE absorbed the ERDA program in a reorganized form, along with its continuing need for cooperation with the private sector.

1 The term "private'sector," as used in this report, includes the total group of energy-related organizations. that are not associated with the federal government, plus all federally-related energy delivery organizations, such as the TVA, REA, etc. As used by the committee, "industry," "academia," and "non-profit organizations" are sub-units of the private sector. 
Despite earnest efforts by ERDA, and now assumed by DOE, the establishment of a sound and constructive relationship with the private sector has proven to be a difficult and elusive task. It is too early to judge whether DOE's policies and organizational structure will result in a more effective approach to the problem, but as noted later in this report, there is every reason to believe that significant difficulties and problems will persist unless important new initiatives are undertaken.

In the research and development area, despite a continuous dialogue between ERDA staff members and industry representatives, there is a general feeling in both government and industry that the ERDA technology development program failed to reflect the best advice and guidance available from the private sector and that the transfer of technology requirements between government research and private manufacturing and production is poor. Demonstration projects pose the greatest challenge, both because of their importance and because of the substantial investments involved, and here the historical record is unimpressive. As will be discussed later, the problems/difficulties commonly stem from federal laws and policies that were beyond ERDA control, but that nevertheless have basic implications for the nature and quality of the governmentprivate sector interaction that can be achieved.

The present study was started early in 1977 in response to a need expressed by the then Assistant Administrator for ERDA Planning. Analysis, and Evaluation and was endorsed by the Administrator of ERDA. The primary purpose was to explore various institutional alternatives that might be employed by the federal government and the private sector to provide an effective coupling between the requirements of the private sector for new energy technologies and the governments planning process to develop these technologies. This also included an analysis of several institutional initiatives that have been tested by ERDA to create an effective working relationship with industry. Based on these studies, the Committee was requested to make recommendations on an appropriate institutional mechanism to improve the planning process.

Two factors led to some indecisiveness in the Committee's early deliberations. First, it was recognized from the start that a meaningful study of appropriate planning mechanisms could not be undertaken except in the context of a broader analysis of how ERDA and the private sector can, and should, interact. It is clear. for example. that a major planning theme should be the question of how government-supported technology can be transferred to the private sector at the earliest possible opportunity. Accordingly, the committee decided to include this larger 
issue as part of its charge. while concentrating on issues that specifically relate to the RDED planning process.

More important was the recognition that initiatives by the new Carter administration would result in substantial changes in the ERDA organization, and of course, this did occur with the formation of the new DOE. The Committee was concerned whether the findings of the study, based on the ERDA experience and organizational structure, would also be relevant to the new organization whose features were as yet undefined. As the studies continued, it became clear that the key elements of the Committee's thinking were broadly applicable and largely independent of specific organizational approaches. Toward the end of the Committee's work, the structure of DOE became known, and it was possible for the Committee to use this information to orient its conclusions regarding a suitable planning mechanism.

In conducting its studies, the committee used a variety of data sources. The backgrounds of the committee members reflected various types of experience, including senior technical positions with energy and other industrial companies, executive positions in various government agencies, lawyers versed in government affairs and energy matters, and non-profit foundations and professional societies. Every member of the Committee has had a long career working close to the interface between the federal government and the private sector.

The Committee had extensive discussions with ERDA management, requested written material from various industrial sources with experience in the energy field, and also commissioned a series of "background papers" from independent consultants. Issues chosen for in-depth study by the consultants included some with important policy implications for the questions under consideration, and examination of the government-industry interfaces in representative segments of the energy industry.

The background papers are useful resource documents in their respective subject areas and are worthy of more detailed examination by those interested in pursuing the study in greater depth. While the views and opinions expressed in these background papers are those of their authors, they were used in the deliberations of the Committee in arriving at its own conclusions and recommendations. Accordingly, they are included in a separate compilation of background papers identified as a Background Information volume to this study available in the National Research Council archives. 


\title{
CHAPTER II
}

\author{
THE GOVERNMENT ROLE IN ENERGY RD\&D
}

The criteria used by ERDA to decide on new projects were outlined to the New York Society of Security Analysts in a paper presented by C. B. Smith, special Assistant for Application Planning, on January 12, 1977. In the presentation it was pointed out that when a new technical option for energy production or conservation surfaces, the first question to be answered is whether the private sector is capable of exploiting the option by doing the research, development, and demonstration in a timely fashion without government participation. If the answer is "yes," which presumes that the option is marketable in the near future on * a profitable basis, the government should not enter the picture unless the private effort falters. If the answer is that the private sector is not ready to exploit the option. the next consideration is whether the public interest. including such issues as economic stability, national security. and international energy strategy will benefit from timely exploitation of the option and therefore justify the contribution of federal support needed to bring it to a marketable stage. A positive answer justifies consideration of the project for government support.

Emphasizing that the role and nature of federal support for a new option must be flexible and decided on a case-bycase basis, the ERDA presentation detailed the variety of criteria used by the agency to determine the form and extent of federal participation. Throughout, the philosophy was for the agency to turn the reins over to private industry as quickly as possible. It was emphasized that ERDA is not

thorized to subsidize widespread use. It was made clear, wever, that ERDA can aid in the development through the age of initial commercial introduction, if necessary, but not in widespread diffusion of the new option into the market.

A fundamental requirement for RDED planning is the existence of a national energy plan that is understood and generally accepted by the public, by congress, and by the private sector. Moreover, and particularly when a technical 
energy option must be pursued from research to the demonstration stage, the plan must have a reasonable assurance of stability over at least seven to ten years. Recognizing that flexibility must be maintained in order to accommodate new information and technological options that may appear in the future, an essential element for successful collaboration between government and industry is mutual confidence that agreed-upon commitments of financial and technical resources will be honored. Erratic program starts and cancellations, particularly without in-depth consultation with industry, make it extremely difficult fo: a senior industrial executive to recommend that his compan: "go with the government." The committee considers the question of program stability to be of the utmost importance in achieving a successful DOE/private sector interface. Chapter VI of this report discusses this issue in greater depth.

Effective collaboration between DOE and the private sector requires effective communication between the two. Final decisions regarding the content of DOE programs must be made by the DOE staff members that bear the responsibility for the disposition of public funds and resources. However, a free exchange of ideas and the ability to call on leaders from industry, universities, and other non-governmental organizations for suggestions, advice, and constructive criticism is obviously highly desirable. Input from industrial sources may include proprietary data and findings that are disclosed only on the basis that they will remain confidential between the parties involved. When $i t$ is to the advantage of DOE to receive such information, the system must insure scrupulous adherence to confidentiality agreements.

Whenever industrial representatives interact with government personnel on matters of their own concern, the possibility exists of conflict of interests between their concerns for their own company and the concerns of the government. A considerable body of legal and regulatory conflict-of-interest guidelines exist to guide such intentions. Progress in meeting our energy needs will be frustrated, however, if the restrictions are so severe that they preclude effective communication even when it is vital to the overall national objectives. As will be evident in the discussion, the Committee is convinced that we have reached this point.

To examine this question in depth, the committee commissioned a study paper on the laws that regulate communication between DOE and the private sector. Chapter $v$ contains an analysis which indicates that there is reason for serious concern in this area. Because of the importance 
of this subject, the commissioned study paper is included as an appendix to this report.

If DOE is to accomplish its desired goals, it is clear that there must be an effective participatory RDED planning mechanism, and also that sound working arrangements must be established for the management of joint projects with industry. During the research and advanced development phases of a new energy option, cooperation between DOE and ndustry will often be mutually advantageous, since market oncerns and proprietary considerations may still be far in he future. As the engineering and demonstration phases come into the fore, however, greater complexities arise in achieving a satisfactory partnership.

In most instances, it is the industry and not the government staffs who have the market-oriented experience and know-how to translate a successful development option into a commercially viable prototype. Certain demonstration projects may draw on proprietary data and skills in order to optimize their chances for success. At the same time. patent rights are sometimes a problem between the government and its industrial counterpart.

While ERDA, during its brief life span, stressed its desire to be flexible and equitable in joint ventures with industry, the Committee $f$ inds that in many instances the record falls short of these good intentions. Various contributing factors are discussed in later sections of the report, and it will be noted that the origin of some of the difficulties is beyond direct agency control.

The Committee did not conduct a study of governmentindustry contracting in the energy area, since its major attention was focussed on RDED planning mechanisms.

Nevertheless, the issue arose frequently during discussions with industry representatives. Considerable information was available to the committee in the findings of the study papers and from the experience of Committee members. Although the Committee did not have time to study the government side of the contracting interface, the committee did consider this problem sufficiently significant to warrant drawing attention to it.

In addition to the need for maintaining effective ommunication between the DOE staff and industry representatives, another requirement for effective DOE planning is a formalized mechanism for injecting a balanced private sector viewpoint into the decision-making process by which DOE determines its future RDED program. A formalized advisory mechanism, drawing on external expertise to help guide program planning, is a technique that has been widely and successfully used both within and outside of government. 
One of the background papers commissioned by the committee consists of a review of various advisory mechanisms used by government agencies to good advantage. In Chapter. VII, the Committee analyzes this background experience and recommends an Energy RDED Advisory Board which the Committee believes can best serve DOE needs. 


\title{
CHAPTER III
}

\author{
THE ERDA (DOE) /PRIVATE SECTOR RDED \\ PLANNING INTERFACE
}

The change from the organizational structure used by ERDA to that used by DOE requires a different approach to maintaining effective communications with the private sector. In ERDA, the management of each major technology development was assigned to an Assistant Administrator with complete responsibility for the research, development, and demonstration projects in that technology. The DOE organization, on the other hand, places complete responsibility for the research phase of all technologies under a single Director of Energy Research, the development of all technologies under the Assistant secretary for Energy Technology, and the commercialization of all technologies, with the exception of Conservation and Solar Technologies. under the Assistant Secretary for Resource Applications. An Assistant secretary for Conservation and Solar Applications has responsibility for the commercialization of these two technologies.

As an example of the effect of this change in organization, it was relatively easy in the ERDA organization for a company interested in fossil fuel technology to communicate with the responsible office within the government. In the new DOE organization, three different organizational offices may have to be contacted to cover the complete fossil fuel technology RDED cycle. The lowest organizational point at which a total perspective on fossil fuels can probably be found is at the level of the Under secretary of DOE. Since the technology development process does not naturally lend itself to neat

compartmentalization into research, development, and :monstration phases, it may be more difficult to immunicate effectively across the DOE government/private sector interface.

One of the principal drawbacks of the ERDA organizational structure was the problem of making priority judgments among different technologies. Since the individual technology development programs were organizationally separate, the priority judgments usually 
were not made until the requirement for project funding was significant enough to come to the attention of the responsible Assistant Administrator. At this stage, sizable funds usually had already been expended and heavy organizational commitments made. This greatly complicated the problem of making objective choices between promising and less promising projects in different technologies. This delay in making the hard choices has the obvious drawback of wasting resources on less promising projects long after they should have been dropped. In the new DOE organization, on the other hand, the opportunity for making priority choice: is built into the organizational structure at all stages 0 : the development cycle, starting with the research phase and extending through the development and into the demonstration phase. Funding constraints imposed on each of the Assistant secretaries with responsibility for a particular development stage will force the program. managers to weed out the less promising ideas or technologies early in order to find support for the good ideas.

The Committee cautions DOE that this change in organization may not improve the effectiveness of the total U.S. energy technology development effort. The ERDA organization provided for a simple communication interface in each technology area but found it difficult to make priority choices. The DOE simplifies the priority choices. but potentially complicates the communication interface with the private sector. Management must be sensitive to and compensate for the inherent weakness of whichever organizational structure exists.

The-ultimate objective of private sector participation in government planning is to provide for more effective diffusion of government-supported technology developments in the competitive energy industry. To achieve this objective, two criteria must be satisfied: 1) the horizon of the RDED planning process must include commercialization and 2) there must be suitable mechanisms to provide for the transition of a government-supported technology development into commercial use. While effective participatory planning is a significant first step, the success of the enterprise depends heavily on the effectiveness of the technology transition mechanism. The Committee did not study this problem. The reader is referred to an ERDA (DOE) study by Demonstration Study Task Force under the Chairmanship of $\mathrm{C}$ Robert Charpie, which specifically addressed this issue..

1"The Demonstration Project as a Procedure for Accelerating the Application of New Technology" by the Charpie Task Force, Feb 1978 (DOE/RA-003/1). 
A basic premise in planning the government-supported RDED program is that the private sector has the paramount role in the development and commercialization of new energy technologies, and that the federal government is responsible for planning, initiating, stimulating, and encouraging the development and demonstration of those new technologies that industry will not support on its own. planning such complementary federal RDED energy programs without leaving important gaps and at the same time avoiding unnecessary iplication requires both an awareness of the technologies quired by the future energy market and information on ivate sector in-house RDED activities. However, much of their information is held as proprietary information by individual companies.

The required planning information varies in nature, depending on the stage in the development cycle. In the early research or invention stage. where promising technological options are considered for initial exploration, market sensitivity is minimal. As the more promising technological options advance through the development phase and approach demonstration for eventual diffusion in the industry, an increasing amount of information on the competitive aspects of the market is required. The successful diffusion of a new technology in the market depends on strong "market-pull" forces for the particular technology. These forces are the summation of many subtle and some obvious factors comprising the competitive market. These factors usualiy cannot be neatly tabulated, evaluated, and then translated into a successful market decision. In most cases, the assessment is highly subjective, and is sometimes contrary to the available objective evidence. Corporate managers routinely make judgments based on their perception of and sensitivity to these factors.

To familiarize itself with the actions taken by ERDA to develop the type of planning information required, the committee was briefed by the Assistant Administrators (AA) responsible for individual technologies, or their representatives, and the Assistant Administrator (AA) for Planning, Analysis, and Evaluation on their perceptions of the ERDA industry interface. Generally, the technology AA's s-it that they had very little difficulty maintaining itact with the industry in their technology sector. vever. they implied that much of this interaction involved project selling by industry representatives rather than sharing of technical information. In several cases, they seemed to be primarily concerned with getting additional competent staff members who could bring industry experience into the management of their programs. 
Very little concern was expressed by the technology $A A^{\prime} s$ on their need for information on the industry's in-house research and development programs, which is usually kept as proprietary information by individual companies. This apparent lack of concern surprised the committee, since details of the in-house program are important in planning a complementary government RDED program. While the committee was not in a position to analyze this apparent lack of interest, the members of the committee contended intuitively and perhaps erroneously that either the ERDA RDED planners wanted to avoid areas of presumed special industry interes and to plan their programs accordingly, or that the industry's in-house RDED was simply disregarded in formulating the federal program. However that may be, the Committee is convinced that industry in-house RDED activity must be considered in planning the federal program in order to prevent unnecessary duplication and to avoid important program gaps. Furthermore, if the federal program duplicates the industry's in-house program in some important areas, this can seriously affect industry's opportunity to establish a proprietary position, which is one of the primary motivational factors in industry's support of research.

The AA for Planning. Analysis, and Evaluation, who was responsible for ensuring that the balance between different ERDA technology development programs was consistent with the priorities of the National Energy Plan, felt seriously handicapped by the lack of adequate information on the technology required to satisfy the future energy market. Unlike the other AA's he was also seriously concerned about the lack of reliable information on the industry's in-house technology RDED program, needed to evaluate the adequacy of the complementary federal RDED program.

The Committee reviewed ERDA's efforts to improve the planning information base and to obtain the necessary industry and academic expertise to assist in the planning process. These efforts included the use of advisory committees inherited from its predecessor agencies: the use of modeling techniques to determine the future behavior of the energy market, as a basis for estimates of future technology requirements; the development of survey techniques that can gather essential information on the industry's in-house RDED program; and actions to enhance 1 level of industrial management expertise available to the ERDA headquarters staff. These are discussed in the following paragraphs. 
When ERDA was established in 1975, the new agency inherited a number of advisory committees that were associated with the technology programs moved into ERDA from other federal agencies. Some of these committees were terminated while others were continued with re-oriented charters. When ERDA was absorbed by DOE on October 1, 1977. it had four functioning advisory comnittees involved

:ectly with energy technology. These included:

1.) General Advisory Committee, which advised the Administrator on broad issues cutting across specific program areas.

2.) Fossil Energy Advisory Conmittee (previously called General Technical Advisory Committee). which advised the AA for Fossil Energy on the Fossil Fuel Technology Program.

3.) Lignite Advisory Committee, which advised the AA for Fossil Energy on the functions of one specific energy research center at Grand Forks, North Dakota, which conducts ERDA's Lignite Coal Utilization Research Program, and

4.) Geothermal Energy Advisory Committee, which advised the AA for Solar, Geothermal, and Advanced Energy Systems on geothermal energy.

When the new DOE assumed responsibility for the federal energy program, the ERDA Committee structure was reviewed. As a result of this review the General Advisory committee was abolished and the Lignite Advisory Comittee was made into a subcommittee of the Fossil Energy Advisory Committee. The Geothermal Advisory Committee, organized by ERDA, was retained to function in its technology area. DOE is currently reviewing the complete advisory requirements of the Department and expects to design a suitable structure that can serve the broader requirements of the new agency. The recommendations in this report are expected to be considered in devising a suitable mechanism. The carry-over committees from ERDA will probably be folded into the new advisory structure.

\section{ermination of Future Technology Requirements}

ERDA conducted a Market oriented Program Planning study (MOPPS) to determine the energy technology required in the year 2000. This study used a model of the energy demand in three consumer areas to project future market energy requirements. The consumer areas covered the residential and commercial sectors, the industrial sector, and the transportation sector. Two different growth scenarios were 
used, one with a low, 2.3\%, and the other with a high, 3.6x, GNP growth rate. Initial assumptions were made to cover such issues as oil and gas price regulation, market pricing mechanisms, OPEC behavior, economic and political stability. the federal role in the energy partnership. and the anticipated population growth rate. Historical energy production and consumption data covering the years since 1975 were used in the model as a basis for the projection.

The Committee did not have an opportunity to study thi project in sufficient detail to judge its quality. Severa comments are in order, however. A data base with a two-year time depth, although it may be comprehensive, is extremely weak to support a 25-year projection into the future. This is particularly true if one considers the turbulent nature of the energy market during this brief period. The Comittee is also uneasy about the fidelity of any model to simulate the future market behavior. The randomness and non-linearity of many of the forces that affect market behavior defy modeling in the conventional sense. The Committee is also concerned that an adequate sensitivity analysis of the model be made to determine its response to changes both in the initial assumptions and the market survey data.

However, the Committee recommends the continuation of efforts to understand what the future market demands will be. DOE should also be encouraged to relate its efforts to the market behavior studies conducted by the Department of commerce and major energy corporations, in order to have access to their data and to refine its own understanding of future energy technology requirements.

\section{Survey of Industrial In-House RDED Activity}

ERDA contracted with the Industrial Research Institute Research Corporation (IRIRC) for a study of the feasibility of conducting a survey of the energy industry companies to determine their in-house RDED activity. The objective of the survey was to determine the willingness of companies to provide reliable and comprehensive data on their in-house energy RDED. In order to protect the proprietary nature of these data, it was agreed from the beginning that before survey results were turned over to ERDA or made public, $t i$ survey contractor would aggregate the data from all companies within an industrial sector into a single data set, with all company identification removed. The industry response to the survey was uniformly favorable. In all cases companies wanted absolute assurance that the confidentiality of their original data would be maintained. They also suggested that the research categories in the survey form be standardized in order to both simplify the 
data collection and improve the accuracy of the data aggregation process.

As in the case of market-oriented studies, the committee agrees that effort in this area should be continued. The Committee is somewhat skeptical, however, that the aggregated sanitized data will really satisfy this part of the planning information requirements. However, it should be an improvement over the current situation, where no or

ry limited proprietary information is available. The immittee suggests that experimentation be continued to urvelop the required information on industry's in-house RDED activitiès.

\section{Enhancement of Management Expertise}

In the discussion with ERDA officials there was general recognition that the federal RDED planning process and the program management could be made more responsive to the technology requirements of the energy industry by the infusion of industry experience into the program management staff.

The AA for Fossil Energy persuaded the American Society of Mechanical Engineers to organize a consortium of professional engineering societies. identified as the Engineering Societies Commission on Energy (ESCOE), to provide independent objective consultation and advice on the planning and management of the fossil energy RDED program. As it is set up, ESCOE operates an Engineering Residency Program in Washington, D.C. under contract to ERDA (DOE). The participating societies assist in recruiting a staff of ten to twelve highly qualified people with diverse backgrounds, half from industry and half from academia, to serve for periods of up to two years as employees of ESCOE. While the primary objective. of ESCOE under ERDA was focussed on fossil energy technology, the scope of ESCOE's responsibilities is to be expanded under DOE to include other energy technologies. The success of this program depends on the willingness of companies and universities to recommend and release experienced staff members of the caliber required, for a period of up to two years.

Another effort to bring industry expertise into the ERDA 'gram management was the initiation of a Pilot Product Planning Team, patterned after a concept commonly used in industry to bring a new product into profitable commercial production. On a pilot basis. ERDA assembled a team of individuals either retired or on loan from industry, who were experienced in managing new ventures, to work closely with the ERDA program management in the development of a thermally activated heat pump. While this is a common 
industry practice, it seems somewhat out-of-place in the ERDA (or DOE) framework where the market rewards or penalties are not the motivating forces. The early marketoriented thinking by federal program managers, however. should upgrade the usefulness of the technology development products. Even though such a Product Planning Team may ask some of the right questions as a new product.proceeds through the development process, the committee does not consider this concept to be an adequate substitute for participatory planning.

The Committee recognized ERDA's concern to improve botn the level of industry-related expertise and the quality of information of market behavior available to the federal energy RDED program managers. The Committee agrees that these are important objectives, but is convinced that even if these initiatives are completely successful, they cannot be considered substitutes for an effective participatory planning mechanism required by the energy partnership. In all of these initiatives, the critical feedback loop from the technology user or operator bringing the economic realities of the competitive market place to the technology development planner is missing. This feedback signal provides the basis for effective debate between the technology developer and the users, thereby testing the responsiveness of the technology development program to the future requirements of the market. While the Committee's attention was di rected at ERDA. these considerations have broad applicability and are also relevant to the DOE energy RDED planning process. 


\section{CHAPTER IV}

\section{INDUSTRY PERCEPTIONS OF THE ERDA/PRIVATE SECTOR INTERFACE}

As part of its studies, the committee considered it important to gain an understanding of reasonably representative current industry attitudes toward involvement of the federal government in energy RDED. It was appreciated at the start that the diversity and size of the energy industry meant that only a sampling of viewpoints could be obtained. Moreover, even within a single segment of the industry, a wide variation in perceptions from one private company to the next was expected. It was decided. therefore, to concentrate on three energy technology areas characterized by important RDED requirements, each chosen because it reflected a unique set of problems involved in the interface between ERDA and the private sector.

The technology areas chosen for in-depth study include the. syn-fuel industry, the nuclear power industry, and the solar energy industry. Syn-fuels' is an area where substantial RDED history has been accumulated within the private sector in the United States and abroad, and where further progress, to a great extent, requires large demonstration projects. The experience of the nuclear industry differs from the syn-fuels experience because of the heavy Federal involvement in nuclear research and development, as well as the extensive experience gained through the Naval Reactor Program. Finally, solar energy was chosen for study because it is an emerging energy option and, unlike the case of the syn-fuels and nuclear industries, the solar energy industry includes a large number of relatively small companies.

It was originally intended that in-depth background tdy papers. would be commissioned for each of the three !as, but it was not possible to locate an acceptable urdrce for the syn-fuels study within the time constraints established by the committee. Therefore, in the.syn-fuel

The term Syn-fuels as used in this study refers to those gaseous and liquid fuels upgraded by conversion from solids such as coal, shale, tar sands, etc. 
area, information was collected by sending questionnaires to a representative group of companies engaged in syn-fuel projects and by interviews with private sector representatives. A tabulation of the questionnaire responses and the full texts of the background papers covering for the nuclear and solar areas are included in the Background Information volume of this study available in the National Research Council archives.

The following is a summary discussion of the pertinent views expressed by the industry responses in the three technology areas.

\section{SYN-FUELS}

The syn-fuels area poses certain unique protlems for DOE/industry cooperation, largely because most of the knowhow relating to syn-fuels, technology is in private hands and has reached an advanced stage of development. While it would be rash to state that new technological breakthroughs will not occur in the future, industry responses emphasized that present knowledge is sufficient to warrant undertaking large and costly demonstration projects as the next step in the development of the technology.

According to industry, syn-fuels technology becomes a federal RDED concern because of the very large financial commitment needed for demonstration plants, and because the most optimistic forecasts indicate that, while syn-fuel development may be essential to national security. syn-fuels will not be competitive with products refined from petroleum and natural gas for a decade or more, in light of OPEC pricing flexibility, which is essentially independent of the cost of production, and the extent of government regulation of prices. From the viewpoint of planning the national energy future, it is of the utmost importance that operating experience and accurate cost data for syn-fuels plants be obtained as quickly as possible. Industry is unwilling or unable except in a few cases involving larger corporations in demonstrating company-originated processes, to commit major resources without reasonable assurance of a timely and adequate return on investment. The federal role as catalyst and financial backer becomes essential to early progress.

The history of government/industry collaboration on s: fuels projects has been a less than happy one. Technical issues have raised some problems, but the major controversies arose over project management policies, environmental restrictions, cost-sharing formulas, pricing. and even federal land-leasing policies. In spite of this. there is general agreement among industry representatives that it is important for demonstration projects to proceed 
promptly, and that industry will cooperate fully within its economic means in the planning and implementation of such projects, provided that private sector participation is encouraged and that formulas can be devised to protect proprietary interests.

\section{NUCLEAR POWER}

Industry representatives acknowledge the leadership role

the government in nuclear research and development, but $: 1$ strongly that the management of demonstration plants aimed at the commercial energy market should be in the hands of private utilities. They contented that when a government staff assumes this responsibility. costs are not constrained by commercial standards because of a tendency to force the development to satisfy naval reactor performance criteria and thereby prolonging the development phase. This is further aggravated by the insistence on levels of quality control and equipment reliability which may not improve plant safety but result in substantial cost increases.

As an example, industry proponents point to the clinch River Breeder Reactor project. Even though the reason for termination was the president!s stand on nuclear weapons proliferation, the project was already in considerable trouble because of major cost overruns and technical differences between the government and participating industry staffs. Begun as a cooperatively managed project. essentially complete control was taken by the government in the later stages, as its share of the projected costs kept escalating. According to the expressed view, the program direction increasingly veered from the proper objectives of a demonstration project for eventual commercialization towards the objective simply of development, as the degree of ERDA management control increased. Moreover, progress was slow and with continuing cost escalation, invited efforts for termination by its critics.

While the issues are complex, the attitude of the nuclear industry can be summarized by its desire for a stronger voice both in DOE program planning as well as in program implementation. It would be unfair to say that ERDA failed to recognize the validity of this point of view (the nch River program was originally under the direction of a nt management operation; with the government directing .... $R E D$ and the nuclear reactor, and the utilities [ 753 electric companies]. in the form of a Project Management Corporation, directing the power-generating portion of the project. These were later integrated, with the government. assuming a dominant role when its share of the costs kept escalating). Experience to date indicates that, where the possibility of commercialization is the end objective, a 
strengthening and formalization of the private sector role is needed for the future.

\section{SOLAR POWER}

Practical uses of solar power technology are at present limited to hot water and space heating applications, with a large number of companies (mostly of small size) engaged in the production and installation of flat plate solar collector systems. More advanced uses of solar energy, st as space cooling, thermal electric power generation. photovoltaic power generation, wind power, and ocean thermal energy conversion, are still largely confined to RDED activities supported primarily by DOE. Research and development participants include both large and some small companies, a few with sophisticated technical resources.

Except under uniquely favorable circumstances, even the simpler applications of solar energy. such as hot water and space heating, are at best marginally competitive on the basis of current equipment costs and market energy prices. Because of the federal government's strong desire to stimulate greater use of solar energy as a secondary energy source, leading to increased production volume and reduced costs, a host of demonstration projects has been initiated to gather long-term operating data to provide the basis for advancing technical objectives and lowering cost. There is little doubt that the appeal of an inexhaustible source of energy from the sun has a powerful fascination in the public mind, but it remains to be seen whether the efforts toward demonstration will yield sufficient new data and insights to bring these objectives within reach.

Members of the solar energy industry have ambivalent views about the proper role for the federal government in helping to advance the field. Manufacturers of flat plate solar collectors believe that the government should not engage in technical development activities, lest the opportunity by the private sector to establish proprietary rights be undermined. On the other hand, companies would like to see the government, or a suitable trade association. lead the way in developing reasonable standards for performance that will prevent the sale of shoddy products and avoid public disenchantment. There is the parallel concern, however, that overly stringent standards may be promulgated. which would raise the costs of compliance anw thereby slow the diffusion of solar energy technology into the commercial market.

In the more advanced areas of solar research and technology. there is general agreement that DOE has a legitimate role in providing some of the resources essential 
for timely progress. As in the other energy areas, members of the solar energy industry join in the viewpoint that the government role should be supportive, and that new technology. should be transferred to the private sector as quickly as possible.

Despite the differences among the three energy industries, the studies in each area reflect considerable unanimity on the role that industry believes the government hould fill in energy RDED. Specifically, the government hould concentrate its RDED activities on promising energy iptions that the private sector is unable to support on its own. As the development of such a new energy option reaches the demonstration phase, private sector feels that federal support should be phased out and that industry should take over. There is a clear recognition by the industry that the government has a legitimate role in assuring that critical technologies are available for use by the industry when needed.

It is generally accepted, however, that certain new energy options will not come onstream within the time frame required for national security and other reasons unless government support is added to the private sector effort. In the area of fundamental research, for example, the government has accepted the role of being a major supporter of the national effort across the spectrum of science and engineering: increased government effort in the different energy areas fits into this conception of the government's role.

Developmental projects should be undertaken by the government only when private industry is not mounting an adequate effort. A similar criterion should also apply to the case of major demonstration projects, which in every instance involving the government should be carried out as a cooperative effort with industry. In some cases, because of national interests, commercial-sized demonstration projects may have to be started even though they may not be able to compete in the market with the price flexibility advantage of imported oil.

In short, there is broad agreement within the industry that federal RDED program planning should complement and be upportive of the private effort and should not promote overnment initiatives that cannot be effectively meshed ..ith private industry plans. The government effort should concentrate on longer-term goals, with private industry pursuing the near-term energy options within the normal competitive constraints of the marketplace.

Most industrial executives question how federal RDED planning can proceed rationally in the absence of a 
generally accepted and reasonably stable national energy policy. Since DOE should not duplicate the near-term technological objectives of the private sector, its planning should be aimed primarily at longer-range goals, e.g.. helping to insure that new energy options, which are not yet commercially attractive, reach that state within a time period that fits the national needs. Since government energy planning thus far has been characterized by numerous changes in policy, which in turn have resulted in shifts and discontinuities in program directions, many industrial executives are wary of committing private resources to an uncertain future.

There is also a prevailing opinion that government planning has been accomplished without the benefit of adequate input from the private sector. Since industry will eventually bear the burden of translating the products of government RDED into commercial practice, most private sector representatives feel that some organizational mechanism should insure that industrial viewpoints and ideas have an opportunity to be considered carefully for incorporation into federal RDED planning.

Industry responses recognized that technology diffusion in the market is often a difficult and unpredictable process. Survival of industry in-house technology developments in the competitive market is also fraught with uncertainty. To enhance the survival rate, regardless of who supports the development, the most knowledgeable judgment should be used in planning the program.

Other areas of concern related to government/private sector interaction are the protection of proprietary information when a company reveals such data to DOE, the protection of patent rights, and the potential exposure of individuals and companies to antitrust and conflict-ofinterest accusations based on planning activities undertaken in collaboration with DOE. It has already been noted that these kinds of legal barriers were brought to the Committee's attention early in its studies, and that because of their importance they are explored in detail in a later section of the report. 


\section{CHAPTER V \\ LEGAL_CONSTRAINTS TO DOE/PRIVATE SECTOR COOPERATION}

It has already been emphasized that a primary requirement for effective DOE/private sector interaction is mainţaining open and free lines of communication between the two. Ideally. industry representatives should be willing and anxious to communicate their knowledge and ideas to DOE staff members as a constructive contribution toward optimizing the effectiveness of DOE planning and program implementation, eliminating unnecessary duplication of effort, and insuring the viability of our national energy posture. From the DOE viewpoint, close collaboration with industry is important to insure that technology transfer from DOE to the private sector is accomplished expeditiously, and to serve as a channel through which DOE staff members are kept aware of the commercial feasibility and marketability of new energy options.

As the committee continued its studies, it became clear that there are a number of legal constraints that tend to reduce the ease with which information flows between government and the private sector. In order to gain a deeper understanding of these issues, a background study paper was requested of The Research Group Inc.. Charlottesville, Va.. which made available a team of expert legal analysts. The complete text of this background paper is included in the Appendix to this report.

At the outset. it must be appreciated that the problem of communication is exacerbated by the fact that the motivations and interests of individual private companies will never be identical to those of DOE. The very essence of the free enterprise system is that a company be

ccessful in the market and earn a satisfactory return on is investment. Hence, complete disclosure of proprietary ata and know-how prior to commercial exploitation is often inimical to its own best interests. Even in closely regulated industries, such as the private electric utility industry, there is the continual appearance of conflict between private and public interests: between the responsibility of company management to generate earnings for its shareholders and meet future capital requirements. 
and the pressures on regulatory agencies to keep utility rates as low as possible.

It is precisely to deal with potential conflicts of interest, real or imaginary. that the body of laws and regulations described in this section came into being. While each law or regulation taken on its own can be justified on the basis of past experiences, taken as a whole they represent a significant deterrent to free communication between DOE and the private sector.

In the discussion which follows, the principal legal barriers to communication are highlighted, along with the laws and regulations from which they were derived. Greater detail is contained in the Appendix.

The Conflict with the Government's Ef fort at Openness

The Freedom of Information Act (FOIA: 5 v.S. code section 552). the Government in the Sunshine Act (Sunshine Act: PL 94-409), and the Federal Advisory Committee Act (FACA: 5 U.S. COde Appendix 1, Section 1) are all directed toward the desirable ends of increased public awareness and access to the process by which government decisions are made, and the avoidance of conflict-of-interest on the part of government advisers who contribute to the decision-making process. In working toward these goals, an undesirable side effect is that barriers are raised to the ability of DOE to take advantage of the innovative capabilities, managerial talent, and experience of the private sector.

FOIA was enacted to provide formal notice, by publication, of government actions to persons affected by federal agency activities, and to make agency documents available for inspection by an interested public. The Act does contain statutory exceptions that justify an agency's refusing to disclose information that falls within one of nine exempt categories, including "trade secrets and commercial or financial information obtained from a person and privileged or confidential."

As pointed out in detail in The Research Group. Inc.. - paper however, a private company wishing to aid DOE by divulging proprietary data or privileged information has good reason to doubt whether DOE can preserve its confidential status. To begin with, the courts have interpreted the nine exemption provisions quite narrowly. Moreover, nothing in the Act prevents any agency from voluntarily disclosing the confidential information it acquires, although recent court decisions in "reverse-ForA" suits have ruled against agency disclosure of certain exempt information. Whether the rulings have, in fact, prevented 
disclosure of exempt information in other contexts is unknown.

The Committee was not made aware of anything in ERDA's history indicating that it has knowingly engaged in unethical or unprofessional conduct. Nevertheless, there is a lack of clear and decisive legal framework for protecting proprietary information. Litigation may, of course, result in the eventual disclosure of the information. Moreover. he fact that litigation might be necessary to protect

alued data tends to inhibit private sector participation in the DOE planning process.

While FOIA gives the public access to printed material. the open-meetings provision of the Sunshine Act gives the public the right to sit in on the oral deliberations of an agency. As in the case of FOIA, exemptions are provided, but the procedures for closing a meeting to the public are made intentionally burdensome, and the exemptions must conform strictly to court decisions interpreting the law. It hardly needs mentioning that participants in open meetings will probably be careful to exclude from their remarks the kind of input most desired, i.e.. private insights and privileged information gained from experience. Finally, the FACA mandates that the meetings of advisory committees be open. While exceptions to this mandate can be invoked by the agency. the process has also been made purposely difficult to discourage such action. FACA has such broad application that it will tend to keep substantive and controversial issues off the advisory agenda. This will have the obvious impact of discouraging many experts from joining DOE planning and review groups. Open meetings will therefore tend to be empty meetings.

As an additional illustration of the kind of government initiatives that reduce the willingness of private sector representatives to contribute to DOE planning, consider s.555 of the 95th Congress. Ist session, which was under Congressional consideration at the time of this writing. The intent of $S .555$ is to prevent senior government employees from directly benefitting from their government service by controlling the acceptance of employment within industry. A grace period of two years is specified after ley leave the government, during which time they cannot cept private employment with any organization that deals

ith the government in the same area of activity that they were involved in. This prohibition would include all divisions of large industrial organizations with widely different product lines, as long as one division has dealings with the government. One interpretation of the bill, as present ly drafted, is that even part-time consultants to the government would come under its provisions. This would be a major expansion. of a current 
Executive Order which prohibits employment in a production division with which the former employee had dealings as a government employee, for one year after leaving the government. This legislation may never be enacted, but its philosophical intent affects the climate for participation in RDED planning by experts from the private sector.

\section{Protection of Proprietary Information}

It has already been noted that "openness" laws raise a number of issues relating to the protection of a private company's proprietary information and trade secrets when they are made available to DOE. The problem is made even more complex by legal issues other than those specifically relating to openness in government operations.

It is important to note that, in order to carry out its mission of preparing a national energy plan and protecting the energy future of the nation, DOE has been given statutory authority to acquire trade secrets and proprietary data and is under a general instruction to protect such information when it does acquire it. (A similar authority was granted the National Aeronautics and Space Administration in aerospace science and engineering, but the best information available to the committee indicates that NASA has never exercised its rights in this regard.) should DOE invoke this privilege, the question arises as to whether it can indeed honor its commitment to preserve the confidential nature of the material divulged to it.

In the private sector, a trade secret is lost when it is effectively disclosed to other parties. The same is not true, however, when a trade secret is disclosed to a federal agency. Instead, the rule is that the owner still possesses his trade secret under such a circumstance. However, there are so many qualifications to this rule that it provides little confidence to the private firm risking its valuable property by disclosing a trade secret to the government.

The owner of a trade secret who discloses it to a federal agency must continue to treat it as a secret. The typical method of doing so is by use of a restrictive marking on each page of a document containing the secret. The federal courts, however, have not recognized this type of marking as necessarily providing full protection. Indeed, one court has merely stated that there must be a hearing before such information is released (Federal District Court. District of Columbia. International Engineering Co. v. Richards 1973).

Once a trade secret is released by an agency, a private firm has no effective remedy to recover the loss it thereby 
suffers. A suit can conceivably be brought under the Federal Tort Claims Act, but the possibility of success in such an action is untested. Agency employees who wrongfully divulge information are subject to mild criminal sanctions. but legal research failed to reveal a single instance of such a sanction being invoked. The real threat, however, is that a DOE employee will leave the agency, go into the private energy industry, and take confidential information with him. Current law provides the original owner no remedy it all in this situation.

\section{The Protection of Patent Rights}

A patent is the legal right of an inventor to use or practice his invention for 17 years before others can use it. It is given by federal law to encourage the effort and imagination necessary for invention. The holder of a patent may grant a license to others to practice his invention, either on an exclusive or nonexclusive basis.

The policy of DOE with respect to patents for nonnuclear technologies is governed by section 9 of the Federal Non-Nuclear Energy Research $\varepsilon$ Development Act of 1974 (PL 93-577) and by the proposed regulations promulgated in conformity with that Act. Patents covering nuclear technology are governed by the Atomic Energy Act. which vests title to them in the government. Basically, the policy of DOE is to acquire the rights to all patents for inventions arising out of direct RDED contracts. However. there is an exception to this rule. DOE can waive its right to the patent in order to encourage investment of venture capital in energy RDED. Still, the grounds for a waiver are based on broad policy objectives and provide no certainty to a private firm that DOE will waive its right to the patent. either at the time of contracting or when an invention is identified.

There are, in addition, other aspects of DOE's patent policy that create uncertainty and concern in private industry. When a waiver is requested but refused, or if a waiver is not sought by a party contracting with DOE, the inventor normally retains a nonexclusive paid-up license to ractice the invention. However, the value of this paid-up icense can be seriously degraded by DOE granting a license o another firm, which DOE can do if it feels that this action will lead to further practical application of the invention.

Another problem involves "background patents"--those which a contractor developed in an area of energy technology prior to its contract with DOE. Under certain situations. DOE has the right to license these patents in order to 
promote the rapid diffusion of information. Moreover, a DOE contracting officer has the right to review any data and records kept by a DOE contractor. All these patent provisions create serious concern in private industry that valuable business assets may be appropriated by DOE.

None of these patent problems apply directly to joint planning sessions. DOE's patent policy only applies to its RDED contractors, and no participant in joint planning is likely to lose any patent rights in the course of that activity. However, the uncertainties in DOE's patent polic] have created a generalized fear in private industry that jaundices its view toward any dealing with DOE. Private companies are in a competitive business which must generate earnings, and many aspects of the DOE patent policy are a threat to these earnings. One way to improve this difficult situation is to revise patent policies in such a way as to. make them predictable and we11-understood, but also to make them consistent with the preservation of essential and legitimate business interests of the private sector.

Legislation may be necessary to accomplish these objectives.

\section{Organizational Conflicts of Interest}

No firm should be allowed to prepare specifications in such a manner that it gives itself an unfair advantage in later procurement contracting. When DOE contracts to obtain advice, that advice should be objective, trustworthy, and not slanted to promote the aspirations of the advising firm or individual. These two goals may prove difficult to achieve, however, when contracting firms are involved in "organizational conflicts of interest." The issue raised by such conflicts has been debated sporadically in congress over the past 15 years and has resulted in a number of statutes and regulations--some affecting DOE--that create barriers to joint planning.

The existing regulations have two goals. The first is to avoid unfair competitive advantages. These occur when a private party has an opportunity to participate in the initial stages of a program, and thereby gains an advantage in winning the contracts that flow from the program. The second goal is to ensure that the government obtains the most competent, unbiased, and reliable advice. The objectivity of a private party, be it an industrialist or a: academician, who is advising the government on the feasibility of a program may be tainted by the adviser's desire to participate in that program in the future.

The shortcomings of the existing regulations were revealed in detail in the "Bechtel Hearings" before the Subcommittee on Energy Research and Water Resources of the 
Senate Interior Committee, conducted from November 17 to December 5. 1975. The hearings uncovered significant conflicts of interest. which were not revealed under the constraints of current law. As a result of the hearings, both new congressional legislation and a new ERDA regulation were adopted.

The new regulatory solution to this problem appeared as ERDA-PR Temporary Regulation 35, and the legislative solution as PL 95-39. Both efforts require that any firm proposing to do work for ERDA affirmatively identify to the agency any potential conflict of interest. Temporary Regulation 35 applies only to technical and management support services, but requires automatic disqualification of a firm with a conflict. It also prohibits participation in any future work which "stems directly" from the project. PL 95-39. On the other hand, applies to all DOE contracts, but allows DOE officials to contract even where a conflict exists, if it is in the best interest of the United States and if its effect can be mitigated.

From the industry point of view, the problem with both provisions is the undefined breadth of information required. Both require disclosure of all information relating to any possible conflict of interest. The limits of this disclosure are undefined, and indeed probably cannot be defined. One large functional problem is that the scope of many RDED planning activities is uncertain at the time disclosure is required.

For the larger corporation, these problems are compounded. A large corporation with many operating divisions may have hundreds of contracts with various government agencies. Identifying conflicts of interest may therefore be literally impossible, and collecting the data required will certainly be expensive. This alone may keep some large corporations knowledgeable in the energy field from participating in joint planning. Moreover, the prohibition in Temporary Regulation 35 against acquiring a contract which "stems directly" from the original work will certainly deter any qualified firm from joint planning activities.

There are two competing policy factors here: obtaining the best advice and not providing advisers an unfair sompetitive advantage. Whatever the balance that is struck between these two factors in future regulations, the rules must be clear and stable in order to encourage the most knowledgeable firms in the field to agree to give DOE preliminary advice, to the extent their interests permit. In striking the balance, moreover, it should be recognized that what is gained by leaning toward one objective may be offset by failure to achieve the other. 
The Impact of Antitrust Considerations

Another disincentive to the participation of private industry in the planning of $D O E-s p o n s o r e d ~ R D E D$ programs is the threat of antitrust liability. Analysis of the existing laws themselves, however. does not fully explain industry fears in this area.

The Sherman Act has been the basic antitrust law. It prohibited "restraint of trade" and "monopolization." The Act was intended to be broad in scope but was initially interpreted rather narrowly by the courts. To remedy this situation, the clayton Act was enacted in 1914. It prohibited specific trade practices that "may have an anticompetitive effect" and bypassed any governmental reluctance to sue to enforce the Act by enlarging the right of private parties to bring suits for damages under it.

The Sherman and Clayton Acts were followed by the Robinson-Patman Act of 1936, specifically designed to extend this protection to small retailers faced with price discrimination problems. The Federal Trade Commission Act, which was broader in scope, was passed at the same time as the Clayton Act. It created the Federal Trade Commission and gave the Commission power to issue orders, the violation of which is punishable by fines. This Act was also broadened during the depression with the passage of the Wheeler-Lea Amendments in 1938.

Despite this maze of laws, it is possible to eliminate. for present purposes, some areas that private industry might be concerned about. Both the clayton Act and the RobinsonPatman Act pertain only to actual sales or acquisitions: therefore, joint planning discussions could not violate these laws.

On the other hand, violation of the sherman Act only requires a conspiracy to restrain trade or monopolize and is no longer narrowly construed. It is certainly theoretically possible that an industry representative attending a joint planning session could be charged with violating the Sherman Act merely because of his participation in the discussion. Participation alone couid be construed by the Department of Justice (DOJ) as an inference of intent to violate the Sherman Act even though no such intent actually exists. Nevertheless, the participant would have to be in some way engaging in a "restraint of trade." This term, of necessity, has never been precisely defined by the courts.

Nevertheless, the difficulties of proving an antitrust violation do not mean that there is not an antitrust problem here. Being a defendant in an antitrust action is very expensive. Most of the large corporations in the energy 
field are well aware of this from their past experience. The time and costs involved in defending an antitrust suit are often staggering, and this alone can make a conservative corporate counsel hesitant to advise participation in joint planning activities. Demands for discovery of documents can result in disclosure of much sensitive information. regardless of the outcome of litigation.

There are other antitrust threats to joint planning articipants. One is "conscious parallelism." Parallel usiness activity by competitors that is in any way related - o matters discussed at joint planning sessions can be the basis for a law suit. Though the chance of liability is remote, a number of even more extreme theories have generated antitrust suits. Another threat is the Federal Trade Commission itself, which has broad investigative powers and applies standards even more nebulous than those of the sherman Act. Finally, there are some federal courts which sometimes render inconsistent and vague decisions in. this area and prevent prediction of legal results.

The number of possible scenarios that can occur during. after, or in conjunction with joint planning sessions makes it impossible to guarantee participants immunity from the antitrust laws. The only course open that eliminates antitrust liability entirely is to meet with industry representatives individually. Another option is to meet in open session. Unfortunately, the one-to-one meetings also eliminate and the open meetings deter the all-important interaction and debate which is the distilling process used to generate good advise and is the trademark of a good advisory body.

The Committee felt that DOJ should assume an active role in providing a framework for private sector cooperation with DOE. This could be done by prescribing specific guidelines that would protect DOJ's essential interests in preventing violations of the antitrust laws while at the same time clearly outlining the permitted range of activities. As an alternative, or perhaps in combination with the prescription of rules, the DOJ could establish a clearance procedure, which would enable industry leaders to present the specific proposed joint planning activity to a reviewing official or anel in the DOJ for clearance. This would remove any hreat of liability or embarrassment as long as the ctivities were carried out in accordance with the approved arrangements. Of course, if the rules prove to be so restrictive that businessmen are precluded from any substantial interaction with DOE, or if the procedures are so elaborate and time-consuming as to set up procedural roadblocks, they will fail in their purpose. 
DOJ's efforts should be guided by a practical understanding of the way advisory groups function in relation to governmental decision making. The DOJ should also be aware of the self-policing inherent in advisory groups comprised of men with a diversity of backgrounds in business and academia. However, it is perhaps less important whether the rules prove to be such that they permit or discourage private sector cooperation with DOE than it is to have a degree of certainty concerning possible antitrust action upon which businessmen (and government officials) can rely. If practical arrangements for bringir private industry's resources to bear upon the Government's programs to deal with the nation's future energy supply are precluded or severely limited by the antitrust laws. both the government and business executives should be aware of the situation. Rules or procedures that would enable businessmen to make a contribution without personal jeopardy or hazard to their business interests would have great value in achieving the nation's energy goals.

\section{Concluding Remarks}

Throughout this discussion of the legal constraints and barriers to DOE/private sector interaction, certain common threads prevail. It is recognized that it may not be possible to achieve entirely satisfactory solutions to important issues. It has already been noted that the interests of the, government and individual companies can seldom be made completely compatible. Nevertheless, the current legal environment has many areas of uncertainty and unfairness from the private sector viewpoint. Efforts should be made to resolve the legal and policy difficulties in a way that encourages practical working relationships between DOE and the private sector. 


\section{CHAPTER VI}

INSTABILITY AS A CONSTRAINT TO DOE/PRIVATE_SECTOR COOPERATION

In addition to the legal uncertainties which tend to reduce the level of DOE/private sector interaction, certain other factors must also be taken into account when assessing the overall environment for cooperation. One of these is derived from the preoccupation of the industry executive with insuring the future success of his organization. This is particularly true of corporations engaged in the exploitation of major new energy options. since it is recognized at the start of a program that increasingly heavy investments over a period of ten years or more may be required before the new technology. if successful, will reach the marketable stage.

When joining with the government to conduct a cooperative project, the industrial executive naturally expects that the government commitment will be based on a planning commitment similar to his own, and that arbitrary shifts in national policy or agency resources will not curtail the program prior to its proper completion.

Unfortunately, in attempting to fulfill its part of the bargain, DOE suffers from several handicaps. Government appropriations are decided on an annual bassis. and multiyear commitments can be made only under special

circumstances. When government policy and resources are relatively stable, this poses no great hazard. However, when volatile political forces are continually at work, the danger to program stability can be great.

In the energy field, the recent history of government planning and program implementation scarcely inspires conf idence. The committee recognizes that a sound national energy policy requires the resolution of extremely complex issues, and that its stability depends on how well it is supported and understood by the public. The committee is convinced that until reasonably stable national energy policies and goals are established and supported by the public, the full government/industry cooperation will not be achieved. 
It should be noted that the lack of policy stability is most detrimental in the case of demonstration projects, and most severely in large programs requiring heavy investment over an extended period of time. In the research and development areas, where individual projects usually have a smaller dollar value and take less time to complete. commitments made by the government and industry can be fulfilled without much difficulty. It is in the demonstration stage of a new energy option, which paves the way for use of the new technology in the marketplace, that the most serious penalties for policy indecision are exacted.

\section{Multi-year Budget Authorizations}

The Committee spent some time discussing methods by which DOE could better signal to industry its intention to pursue a multi-year program to completion. One procedure that may have promise, providing Congress concurs, would be to employ multi-year authorizations in the budgeting process. While congress usually appropriates on an annual basis, it is possible to authorize specific expenditures or commitments on a longer-term basis. The policy implications of a rolling multi-year authorization; perhaps covering the next two or three years of operations, would help to reinforce the mutual understanding between DOE and its industrial partners.

\section{Management of Large-Scale Joint Projects}

The Committee also wishes to comment briefly on one of the important management conflicts that has arisen in certain past ERDA programs. In large-scale development and demonstration programs funded jointly by government and industry, the issue arises as to which party should be given the primary responsibility for program management and execution. In some instances, quasi-public management corporations have been established to direct the programs. with board membership from both government and industry. Although this is desirable for various reasons, it fails to resolve the basic question of which side of the table should have the final right of decision.

The industry viewpoint is that programs of this kind ar undertaken to make important new energy options ready for commercial use. Since industry has the most relevant background experience and probably the best appreciation of the requirements for successful commercialization, along with the greatest know-how and understanding of commercial practices, it follows that the private sector should have the larger voice in management of the project. 
The government position is equally convincing for different reasons and reaches the opposite conclusion. In many cases, the magnitude of the government's financial contribution overshadows that of the industrial partner. since the proper use of public funds is a responsibility of government officials that is non-transferable. in the event of differences of opinion the government view must prevail:

This, however, is somewhat in conflict with the experience during and after World war II, where the Atomic Energy Commission (AEC) National Laboratories were operated by contract managers. Except in the broad overall direction, there was no participation by the government in the project management or direction. While the contract manager technically functioned as the agent of the government, the overall independence of individual project directors made this a somewhat tenuous connection.

The committee has not studied this matter in detail, and advances no recommendations for the proper conduct of future programs. Decisions should undoubtedly be made on a caseby-case basis, since the circumstances of individual programs will vary. It is clear, however, that a generally accepted set of management principles, arrived at after careful consideration of the relevant issues, will be a great help in easing the working relationships and increasing the attractiveness of DOE/private sector collaboration. 


\section{CHAPTER VII}

\section{THE RDED PLANNING PROCESS}

The Committee's principal assignment was to recommend means by which private sector participation in the ERDA (nOw DOE) RDED planning process could be enhanced. From the start, the Committee was aware of the numerous interactions on RDED matters that take place daily between

representatives of individual companies and DOE personnel. Adding to this flow of information is the exchange of data and views at professional society meetings, the outpouring of articles in technical journals and the trade press, and the information gathered at specialized symposia and workshops (many of which have been sponsored by ERDA). In a broad sense, it can hardly be stated that the DOE staff is unaware of the diversity of private sector views on energyrelated matters.

Nevertheless, the fact that this study was commissioned by ERDA indicates a feeling on the part of at least one segment of the agency's senior staff that the private sector input to RDED planning was inadequate in important respects. According to briefings provided to the committee, this also reflected the views of the Administrator of ERDA: Based on discussions with ERDA personnel, it appeared that a strengthened advisory input was needed in the very practical area of relating emerging new energy technologies to the realities of their utilization in the marketplace.

The training and experience of ERDA, and now DOE, staff members reflected, on the average, a heavy emphasis on technical expertise. But the successful utilization of a new technology is critically dependent on other factors as well. Among these are a realistic understanding of the cost factors, sound financial planning, a thorough understanding of the market structure, proper timing in the introduction of a new product, and an alert sensitivity to the changing competitive environment. For optimum RDED program results. the Committee feels that there must be a continuing interchange of ideas and information between the research and development laboratory and the operating elements ultimately responsible for public acceptance and financial profitability. In their briefings to the committee, ERDA 
personnel responsible for evaluating the federal program priorities have maintained that improved feedback of this kind from the private sector will increase the effectiveness of their RDED planning and program implementation.

virtually all government agencies engaged in technical activities have found it useful to enlist the aid of outside specialists who can objectively appraise their agency's plans for the future and monitor progress. Although they :t in an advisory capacity, outside consultants can help to lentify new opportunities in agency programs, avoid overithusiasm for internally generated "pet" projects, and provide a knowledgeable window to relevant activities occurring elsewhere. In order to fulfill this function. different agencies have used a variety of approaches over the years.

As a first step in its deliberations, the committee commissioned a study background paper by $\mathrm{Dr}$. Lawrence Goldmuntz of Economics and Science planning. Inc.. to appraise the techniques used by government agencies, past and present, to obtain outside advice and enhance the flow of information from outside sources. His report details and discusses several advisory mechanisms used by the National Advisory Committee for Aeronautics (NACA), the various branches of the Department of Defense, the Federal Aviation Administration, and various branches of the Department of Transportation. Dr. Goldmuntz's choice of examples typifies the approaches used by agencies with missions somewhat similar to those of ERDA.

The Committe recognized that whatever mechanism was selected. it would be subject to the constraints of existing legislation and therefore would be inhibited in its effectiveness. of the mechanisms studied, the committee selected the National Advisory Committee on Aeronautics (NACA) and the Air Force Scientific Advisory Board (AFSAB) as suitable structural models that could be used to devise a potentially effective advisory mechanism for DOE. Neither of these two models has been tested under the legal. constriants requiring "openness." The NACA was disestablished prior to the legislation, and the AFSAB usually meets in closed session because of classified information involved in their deliberations. In both, imbers are selected from a broad spectrum of the $0 . s$. chnical and industrial community. with participation npproximately equally divided between members associated with industry. and with universities and other non-profit organizations.

Although they do not provide a unique voice for the private sector viewpoint, these mechanisms have several advantages. First. their structure is conventional and the 
policies and procedures for their operation are well established. second, as has already been noted, their effectiveness in satisfying agency needs, including the need for private sector contribution, has been excellent. Finally, while the legal environment has changed markedly during recent years, the operation of these mechanisms has not been challenged on either legal or political grounds. Industry members have not been constrained by the concern with antitrust or conflict-of-interest charges, and while their experience and knowledge was made available to the government, their status as private citizens serving the government in an advisory capacity also was not challenged

The Committees' recommended structure for the advisory mechanism of DOE includes an Energy RDED Advisory Board, four standing committees, ad hoc committees as needed to study specific issues or programs, and an Executive Committee chaired by the secretary or Under Secretary of Energy, with members from both the DOE staff and the Energy RDED Advisory Board.

\section{The Energy RDED Advisory Board}

The Energy Research, Development, and Demonstration Advisory Board ("Energy RDED Advisory Board") will report to the Secretary of DOE. The Board would consist of eighteen members, each appointed for a three-year term on a rotating basis so that six Board members complete their term each year. IIt is recognized that the FACA limits the life of a committee to two years and the terms of its members to one year. The three-year term is considered important to insure adequate time for familiarization and for useful and productive service.) The committee recommends that Board members may be appointed for two successive terms, but not more than two without an interruption of service. Members are appointed on the basis of their individual expertise and not as representatives of their employer-organizations. An approximately equal balance should be maintained between members with relevant industry backgrounds, and members drawn from other areas including universities and other nonprofit organizations.

The primary responsibility of the Board will be to provide advice to the secretary and his senior staff on matters relating to RDED policy, program planning. and program review. In order to best fulfill these objectives. the composition of the Board should include scientists and engineers of established excellence in energy-related fields, industrial executives with proven technical leadership abilities, senior energy economists, and such other talents and skills as the secretary may deem necessary. 
Two members of the Board should be designated by the secretary as Chairman and vice Chairman, respectively.

\section{Executive Committee}

While the Board should retain a considerable degree of autonomy in establishing its agenda, experience with the Air Force Scientific Advisory Board and similar. advisory groups

idicates that it would be desirable for DOE to have a :rong role in approving the work schedule for the Energy ..JED Advisory Board. Direct participation by DOE senior staff insures that the Board will be responsive to DOE needs and encourages DOE management to turn to the Board for advice when critical issues arise.

It is recommended, therefore, that an Executive Committee of the Board be established which would approve the initiation of all studies by the Board and its Comittees. Once a study is approved, the responsibility for its conduct and completion lies with the Board. The Executive Committee should.be chaired by the secretary or Under secretary of DOE. Other members should include the Chairman and Vice Chairman of the Board, the Director of the office of Energy Research, and such other DOE senior staff members as the secretary may select. The membership of Committees and Ad Hoc Panels should be subject to review and approval by the Executive Committee.

\section{Standing Advisory Committees}

Serving under the Board will be a series of five Standing Advisory Committees, with interests parallel to those of the Assistant Secretaries for Conservation and Solar Applications, Resource Allocations, Energy Technology. Envi ronment, and Energy Research. (No recommendation is made here for the conduct of defense-related advisory functions, which should be handled separately for reasons of security-) The Committees shall be composed of Board Members and Associate Members, with a Member as Chairperson in each case: size should be on the order of six persons.

The primary functions of the Standing Committees will be meet periodically with the appropriate Assistant cretaries, to provide advice on such matters as he may request, to work with the Board on matters of common concern, and to serve as a liaison between the Board and the appropriate Assistant Secretary. 


\section{Ad hoc Advisory Panels}

Specific, in-depth studies undertaken by the Board should be carried out by Ad Hoc Panels formed specifically for that purpose. These studies might include, for example, a detailed analysis of all relevant factors bearing on a proposed demonstration project or an in-depth study of the current status and future market potential of a particular technology. Ad Hoc panels should be chaired by a Member or Associate Member, and should be composed of experts drawn from the Board and its Associates. When advisable, the panels may also include specialists recruited from the outside. Each panel should consist of approximately six members and should be dissolved upon completion of its assigned tasks.

\section{Associate Members}

Thirty associate members shall also be appointed, in order to assist the Energy RDED Advisory Board in conducting specific studies and to provide a core staff to serve as members of the Board's Committees and Panels. Their terms of service and provision for rotation shall be similar to those for the Board itself. The Associate Members should include technical specialists from the broad spectrum of the energy-related fields of science, engineering, and economics. As in the case of Members, an approximately equal balance shall be maintained between individuals with industry backgrounds and those drawn from universities and non-profit organizations. Associate Members should also be appointed as individuals, and not as representatives of their employer-organizations.

The responsibility of Associate Members is to serve as consultants to the Board. Appointment of an Associate Member to a Committee or Ad Hoc Panel can be accomplished expeditiously, since the necessary administrative processing and clearances will already have been completed at the time of appointment as an associate. Through the medium of an appropriately planned information system, Associate Members will be kept continuously aware of DOE plans and programs, and will have the opportunity to interact with senior DOE staff in their respective areas of interest. They thus comprise a knowledgeable group of experts. indoctrinated $j$ DOE procedures and capable of conducting studies on a quic response basis with a minimum of administrative delays.

No attempt is made here to describe the Board's administrative and operating procedures, including the requirement of an adequate administrative support staff. These should be tailored to DOE's preferences, taking into account the prior experience of other advisory mechanisms, 
such as the AFSAB. With the strong, yet not dominating. participation of members from industry in the activities of the Board and its subgroups, the committee believes that this advisory mechanism has the potential to provide constructive and useful private sector participation in the DOE energy RDED planning and program implementation provided that suitable legal guidelines can be established. 


\section{CHAPTER VIII}

\section{CONCLUSIONS AND RECOMMENDATIONS}

A variety of corrections can be applied at various points in the government-industry relationship which. individually and in the aggregate, will contribute to more coherent and timely interaction in advancing energy research, development, and demonstration. However, this is bound to be a slow and piecemeal process at best, and its efficacy is by no means assured.

The crux of the problem is to be found in the separate institutional defenses that government and industry have erected over many years in the name of the public interest and the private interest. This system works well enough when each sector is concerned only with its respective goals and objectives. But it malfunctions when goals and objectives converge, as they do in a time of common danger or national emergency. When the resources of industry have to be coupled with the imperatives of national policy, a different working arrangement is called for. The principle of co-responsibility, where each brings to a common table his resources and talents to achieve a common objective, becomes operative, and the requirements of a collaborative relationship must moderate and reshape institutional defenses. The job cannot be done otherwise. The government's normal roles of regulation and supervision in the public interest are legitimate and necessary, up to the point where their exercise is counterproductive to that very interest.

In the case of energy-oriented research, development, and demonstration, the government has shaped its efforts so that they will dovetail with the commercialization responsibility of private industry. The national energy plan is built on the proposition of collaboration, but it not a self-fulfilling proposition in the absence of workable terms of reference in which collaboration can be genuine and scaled to the proportions of the problems at hand. As long as the arrangements for effective cooperation are flawed. and the national research, development, and demonstration program is saddled with constraints which do not suit it. 
government-industry relationships will continue to be sorely troubled.

- As a consequence of its studies, the committee offers the following recommendations:

1. Private sector interaction with DOE in the area of research, development, and demonstration program planning and implementation can and should be substantially improved

istrengthened. With the private sector responsible for

$a$ production, delivery, and utilization of energy in the uarketplace, and DOE with the mission of securing our energy future, active and constructive exchange of knowledge and ideas between the two groups is essential to the national welfare.

2. A formal Energy Advisory Board along with associated standing committees and ad hoc panels should be established. While DOE staff is able to maintain contact with industry representatives through individual meetings and the normal channels for technical communication, such as professional society activities and symposia, there is a need for a formalized and continuing advisory mechanism with strong industry participation to assist in the formulation of the DOE energy research, development, and demonstration program. Such an advisory mechanism is described in Chapter VII.

3. The committee recommends that the secretary give early attention to a review of the laws and requlations that affect those serving DOE in an advisory capacity, and that steps be taken to provide definitive quidelines controlling such service, which would reduce uncertainties and

facilitate the DOE effort to enlist the very highest caliber of private sector advice. The legal framework for expert participation in DOE's RDED planning must be clarified. However, it is equally important that the framework be designed to encourage the necessary private sector participation and sharing of responsibility for the nation's energY RDED future. Without this needed clarification and encouragement, those who participate in, or cooperate with the Advisory Board may unnecessarily run the risk of conflicts-of-interest or antitrust allegations.

Ifidential data and information in theix possession may :ome public knowledge. Private insights and privileged ormation--the most sought-after kind of advice--may not be forthcoming. Moreover, the comprehensive requirements of the Freedom of Information Act, The Sunshine Act, and The Federal Advisory Committee Act will discourage many excellent advisors from serving in DOE advisory bodies. because of the probable vacuity of the exercise. 
In particular, the committee recommends that serious and prompt consideration be given to:

a. Promulgation of a comprehensive requlation explicitly protecting from disclosure all information not required to be disclosed by 1 aw which is qiven to the Advisory Board in confidence either by its participants or by others. Such a regulation should clearly state that its purpose is to serve as the legal basis of a suit to protect the confidentiality of the information. It will also serve as a DOE pledge to protect confidentiá. information in the Board's hands.

b. Initiation of appropriate leqislation to assure that the confidential disclosure of trade secrets to the Advisory Board will not destroy the element of secrecy necessary to legally protect the secret.

c. Modification of existing DOE patent policies to make waiver, march-in, and licensing determinations as predictable as possible, by providing more objective tests to be applied in such

determinations. The current policies on government acquisition of patent rights leave a sense of uncertainty in the mind of the RDED contractor. The Committee further recommends regulatory action to give DOE contracting officers expanded power. where appropriate, to negotiate for RDED services without acquiring background patents. The exercise of DOE acquisition rights to background patents is equally uncertain in its application and should be mae as predictable as possible.

d. Promulgation of clear and stable regulations governing organizational conflicts of interest. These regulations should remove the current ambiguity surrounding potential losses of future RDED contract opportunities by those organizations that cooperate with, or permit employees to serve as members of the recommended Advisory. Board or its Committees and Panels.

e. Obtaining the cooperation of the Justice Department's Antitrust Division in evaluating th antitrust implications of the Advisory Board's activities. The secretary should solicit from the Division guidelines that structure private sector participation in these activities, in order to comport with Division standards of antitrust scrutiny. 
4. The committee concluded that a consistent management plan and stable funding would be critical elements in a successful energy technology research. development, and demonstration program. The committee wishes to call attention to the fact that typical RDED programs, by their very nature, require many years for successful completion. Especially when large demonstration projects are undertaken jointly by DOE and industry, both parties require assurances that long-term commitments will honored unless new technical information dictates changes termination of the effort. In the absence of a - Latively stable national energy plan, it is often difficult for the government to provide assurances of this kind for programs that require multi-year funding. Along with stable funding, a consistent management plan should be developed and adhered to in order to achieve mutually satisfactory results. The committee emphasizes that without stability of this kind, DOE efforts in research, development. and demonstration will not fully serve their purpose of strengthening the nation's energy capabilities. 


\section{THIS PAGE: \\ WAS INTENTIONALLY \\ LEET. BLANK.}




\author{
Submitted by \\ THE RESEARCH GROUP, INC. \\ P. O. BOX 7187 \\ CHARLOTTESVILLE, VIRGINIA 22906 \\ December 30,1977 \\ to \\ The Committee on Private Sector Participation \\ in Government Energy RD\&D Planning \\ Special Projects \\ Commission on Natural Resources \\ National Research Council
}


THIS :PAGE

WAS INTENTIONALLY

LEET. BIANK 


\section{PROJECT PARTICIPANTS}

J. RAYMOND MIYARES, Project Director

J. PERRIN QUARLES, III, Project Manager

ROGER M. SINGER, Director of Research

DANIEL J. PACI, Director of Research

KENNETH T. BOWDEN, II, Research Associate

JAMES R. PUGH, Research Associate

DAVID K. ROSENBLUTT, Research Associate 
2.

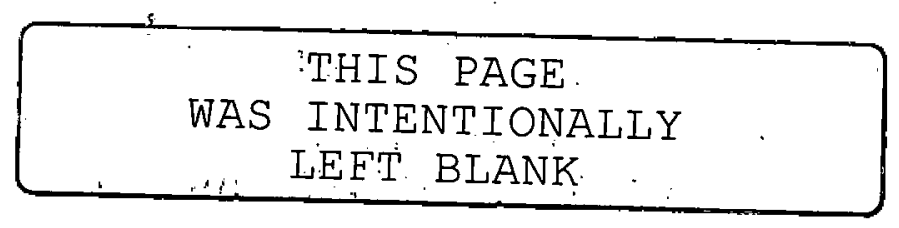




\section{- TABLE OF CONTENTS}

Introduction

The Conflict with the Government's Effort at Openness

The Acquisition and Protection of Proprietary Information

The Protection of Patent Rights

Organizational Conflicts of Interest

The Impact of Antitrust Considerations 

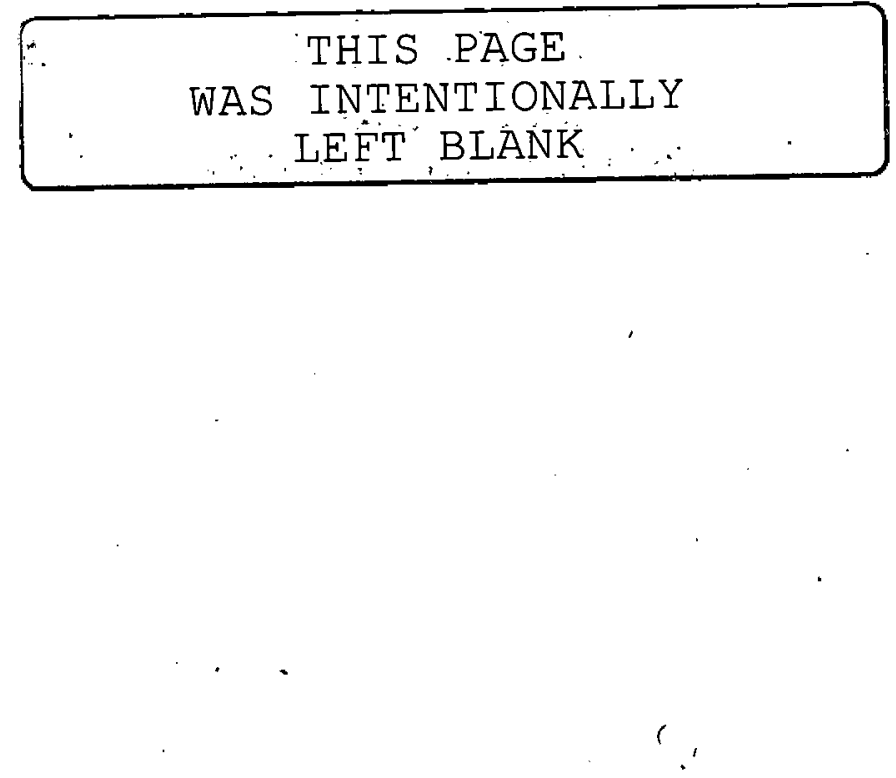
As a preamble to the present study, it is certainly legitimate to inquire whether the U.S. Department of Energy (DOE) needs to engage in joint planning of its research, development and demonstration (RD\&D) programs with the members of the private sector who will participate in those programs. DOE has, at its disposal, a wide variety of data acquisition mechanisms with which it should theoretically be able to obtain all the new information it needs to plan its RD\&D program without the inconvenience of private sector participation. Indeed, the lack of raw information is apparently not at the core of DOE's difficulties in planning its RD\&D programs, it seems unlikely that the Department's.decision-making processes can be substantially improved, merely by injecting massive doses of additional data into it.

Nevertheless, it is clear that institutional mechanisms for the acquisition of raw data relevant to energy matters do not substitute for joint planning between the private and public sectors. Even if it is assumed that the existing statutory reporting requirements and data resources do not substantially overlap, there remains the problem of allowing these mechanisms to be regarded as providing all that is necessary for intelligent planning of RD\&D programs. The difficulty which results from inadequate private sector participation in DOE's RD\&D planning is not primarily in the accumulation of data, but rather in its evaluation, and in the planning of tasks undertaken on the basis of that evaluation. To be sure, there is no reason to believe that DOE's evaluation of the data it accumulates is, on the whole, less vell informed than private industry's. ${ }^{1}$ However, DOE's rientation requires it to maintain a focus on every technology and to be aware of the effects each has on the others. The comprehensiveness of DOE's perspective may arguably be 
supplemented, therefore, by a better understanding of the commercial implementation problems of an energy project. ${ }^{2}$ It may surely be contended that DOE is not sufficiently aware of these difficulties which the private sector encounters once a research and development program is successfully concluded.

One partial methcd of remedying this problem appears to be greater long range joint planning. This planning must consider not only technological problems, but commercial ones as well, and must proceed with an eye toward the development of stable RD\&D program policies. Both government and industry goals must be identified and considered. There must be projections and forecasts by economists and analysts of both as to each project's ultimate commercial feasibility. In addition, it would be helpful to set out, in advance, an overall strategy for each RD\&D project, with criteria and milestones, culminating with commercial acceptance and profitability.

An obvious mechanism for implementing this objective is the creation of a network of advisory boards ${ }^{3}$-made up, in whole or in part, of private sector representatives-which would be charged with assuring that the business reality of commercializing new technology and the problems of policy instability are considered in each phase of the RD\&D planning process. Of course, it cannot be assumed that such a network is the exclusive mechanism by which joint planning can be accomplished. Indeed, any number of alternative mechanismsfor example, greater reliance on academic organizations such as the National Academy of Science, government-industry exchanges of personnel 4 and information, and expansion of the DOE staff to accommodate the acquisition of judgmental information-may be conceived. Moreover, regardless of whether a formally structured board is created, substantial joint planning will continue to occur in more informal contexts as well. 
The present study addresses five specific areas of legal problems which may inhibit the joint planning of RD\&D programs between the private sector and DOE:

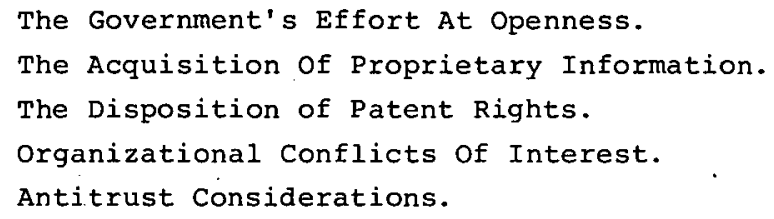

Each of these five problem areas can impact specifically upon a network of advisory boards, such as that contemplated here. However, the present study is not artificially restricted to exploring that impact. Instead, it attempts to address five specific and limited aspects of the law which will directly affect any joint RD\&D planning.

\section{NOTES}

1. Indeed, the view was expressed at ERDA, before the creation of DOE, that its evaluation of the data it accumulated was, for the most part, better informed than the private sector's. Conversation with staff attorney, Office of the General Counsel, ERDA.

2. Telephone interview with Richard Begley, Director of Power Systems R\&D, Research and Development Center, Westinghouse Electric Corp.

3. The Secretary is presently authorized to establish such advisory committees. See 42 U.S.C. $\$ 5816(\mathrm{~g})$. Indeed, a March, 1977, study lists 9 active energy committees providing advisory input to ERDA, before the creation of DOE:

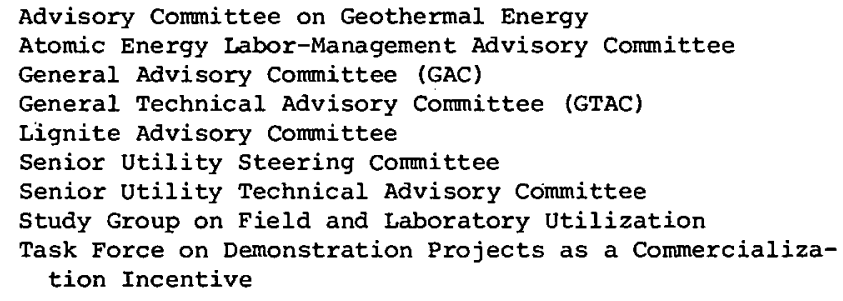

Subcommittee on Reports, Accounting, and Management of the Committee on Governmental Affairs, United States Senate, Energy Advisors: An 


\section{APPENDIX}

Analysis of Federal Advisory Committees Dealing with Energy 11-12 (95th Cong., 1st Session, 1977). One committee which was not listed-perhaps. because it is not, strictly speaking, engaged in policy advisory activities-but which may be considered in evaluating the feasibility of such boards is the Engineering Society Committee on Energy. This Committee recruits engineers from the private sector for a two-year term in Washington. ESCOE engineers, whose salaries are paid by ERDA, conduct analyses of specific technologies in fossil fuels. However, they are charged only with providing technological assessments. Telephone interview with Richard Hill, Director of ESCOE.

4. A model which may be considered in this regard is suggested by the Intergovernmental Cooperation Act of 1968, 40 U.S.C. $\$ 531-535$ and 42 U.S.C. $\$ \$ 4201-4244$. This act provides for exchanges of personnel between federal agencies and either state and local governments or public and private, non-profit universities. 


\title{
THE CONFLICT WITH THE GOVERNMENT'S
} EFFORT AT OPENNESS

\begin{abstract}
Because DOE may be compelled, under FOIA, the Sunshine
Act and FACA, to disclose its decision-making processes, private industry cannot be certain that confidential information it reveals to DOE in a joint planning effort will not be made available to the public. This danger may be most acute with respect to problems posed by products which are near the commercialization stage, and may stifle industry interest in providing exactly the type of information most critical to successful joint planning.

RECOMMENDED: A comprehensive regulation, explicitly protecting from disclosure all information given DOE in confidence, can partially remove the disincentive to aid in the development of energy RD\&D policies and programs.
\end{abstract}

Some energy observers appear to have great faith in DOE's ability to keep confidential those sensitive matters which are communicated to it. Part of this faith seems to stem from the private sector's long-standing relationship and dealings with the U.S. Patent office, which is regarded as virtually "leak-proof." 1 However, it may also be the result of a belief in some sectors that the various comprehensive agency-regulating statutes, dealing with opening the processes of government to public scrutiny, provide sufficient protection for confidential information revealed to $\mathrm{DOE} .^{2}$

Ironically, from the basic structure of these statutes, the Freedom of Information Act ("FOIA"), 3 the Government in the Sunshine Act ${ }^{4}$ and the Federal Advisory Committee t ("FACA"), 5 one may reasonably infer the opposite result. rtainly it would be sensible to predict that efforts to legislate openness in government have the effect of stifling industry interest in becoming involved in joint efforts with DOE to plan RD\&D activities. The basis for such a prediction 
is obvious. It has been observed that one rationale for creating advisory boards to assist in DOE's RD\&D planning is that these boards can offer a perspective on the commercial implementation difficulties which await a newly developed energy technology. Discussion of the specifics of these difficulties, however, may be incomplete if private sector participants cannot feel free to disclose certain types of confidential information and technological evaluations. Yet, they may be especially reluctant to disclose such information anu evaluations without some reliable assurance that DOE will maintain its confidentiality.

Indeed, the one type of information which occasionally causes the private sector to avoid disclosure to DOE is that pertaining to products which are near the commercialization stage. ${ }^{6}$ It.may, therefore, be the case that, while the private sector is generally satisfied with the protection offered its confidential information, that protection is insufficient with respect to some of the information which is most critical to a successful advisory board.

FOIA was enacted in 1966, and subsequently amended, to provide formal notice by publication to persons affected by federal agency activities, and to make agency documents available for inspection by an interested public. However, the Act also contains several statutory exceptions which justify an agency's refusing disclosure of information which falls within one of nine exempt categories. Two of these exemptions seem to apply to the type of energy-related information that the private sector may hope would not be disclosed under the Act. These two protect "trade secrets and commercial or financial information obtained from a person and privileged or confidential;" 7 and "geological and geographical information and data, including maps concerning wells." 8 Nevertheless, 
the courts have applied the nine exemption provisions quite narrowly, and have carefully reviewed claims of exemptions to ascertain whether every element of the applicable provision is met before they have been willing to protect the information from disclosure. ${ }^{9}$

A private company desiring to participate with the government in energy RD\&D planning can expect that it will not itself be compelled to reveal confidential information. 10 Moreover, some reassurance can be derived from the fact that, during its existence, ERDA was never challenged in the courts to defend the confidentiality of any of the information it had obtained. 11 However, nothing in the Act prohibits any agency from voluntarily disclosing the confidential information it acquires. Thus, while the Act does not require DOE to function within a framework that is plainly antagonistic to the private sector's interest in protecting the confidentiality of its information, neither does it require DOE to guarantee the protection that the private sector certainly desires when it assists in RD\&D planning. Accordingly, it has been said:

FOIA is neutral with respect to exempt

information; it neither authorizes nor pro-

hibits the disclosure of such information. 12

Nevertheless, a number of federal courts have begun to grant relief preventing the disclosure of exempt information, pursuant to "reverse-FoIA" suits. This relief has been granted where disclosure violates another statute or an agency regulation, or constitutes an abuse of discretion. 13

The statutory basis for a reverse-FOIA suit can be found in the Federal Non-nuclear Energy Research \& Development Act of 1974.14 In 1975 , a section was added to that Act, providing: 
The information maintained by the Administrator shall be made available to the public, subject to the provisions of section 552 of Title 5 and section 1905 of Title 18, and to other Government agencies in a manner that will facilitate its dissemination: Provided, That upon a showing satisfactory to the Administrator by any person that any information, or portion thereof, obtained under this section by the Administrator directly or indirectly from such person, would, if made public, divulge (1) trade secrets or (2) other proprietary information of such person, the Administrator shall not disclose such information and disclosure thereof shall be punishable under section 1905 of Title 18. . 15

However, the scope of this limitation appears to be limited to information acquired by the Administrator-now the Secretary of Energy - for the purposes of developing an information bank of energy information, as authorized by that section.

On the other hand, the Secretary is authorized by the Energy Reorganization Act of $1974^{16}$ to acquire "designs, processes, specification, and data," 17 including trade.secrets, apparently without any safeguards for the owners of such rights. Moreover:

(e) Subject to the provisions of sections 2161 to 2166 of this title [dealing with atomic energy], and other applicable law, the Administrator shall disseminate scientific, technical, and practical information acquired pursuant to this subchapter through information programs and other appropriate means, and shall encourage the dissemination of 
scientific, technical, and practical information relating to energy so as to enlarge the fund of such information and to provide that free interchange of ideas and criticism which is essential to scientific and industrial progress and public understanding. 18

Whether the term "other applicable law" includes the prohibitions of the information bank section appears doubtful. Therefore, it seems a rather difficult task to prevent disclosure purely on the basis of the dissemination section. 19

An alternative basis may be DOE's regulations. However, regulations adopted by DOE affect the proprietary information only of those who contract with DOE, as opposed to those who might confidentially communicate with DOE in a noncontractual setting. Certain contract clauses, which are to be used in DOE procurement contracts to protect confidential information are specified. ${ }^{20}$ This, however, is the limit of existing regulatory protection.

Regulations proposed by ERDA before the creation of DOE, but as yet not promulgated, ${ }^{21}$ seek to define more clearly the status of confidential information involved in RD\& $D$ contracts. These proposals, however, do not remedy the lack of a regulation explicitly protecting such information from disclosure. 22

In the absence of such a regulation, and in light of the statutory scheme which requires an administrative determination before protection is afforded, a reverse-FOIA action may ultimately be based on an allegation that discretion has been abused in that determination. Although "abuse of discretion" is a somewhat nebulous term, a few grounds for a finding of such abuse have been specified: 
APPENDIX

If the disclosure of exempt information

would constitute a criminal offense, such disclosure would be a clear abuse of the agency's discretion. 23

Moreover:

[T] The disclosure of the exempt information

in the face of government representations

of confidentiality was, on the facts present. here, an abuse of discretion. 24

Nevertheless, the reverse-FOIA cause of action may not go as far as it should toward rebalancing the rights of parties who have an interest in confidential information revealed to DOE. Indeed, a more important factor in this regard may be DOE's own practices designed to assure that information revealed to it by the private sector will not be disclosed. DOE's practice divides the information made available to it into four classifications:

- Information made available as required in a contract with DOE. This data is normally made available to the public.

- Information needed by DOE for internal review. Some of this is edited and published to stimulate inter-industry interest. That which is proprietary is kept confidential.

- Proprietary information which DOE looks at, but does not keep, so that it does not have documentation which can be the subject of an FOIA action.

- Exempt information, including data not relevant to the particular contract involved. 25 
DOE appears to be taking the position that only the first listed classification of information is subject to disclosure. Within the second classification, however, DOE may be willing-as have other agencies such as the Environmental Protection Agency-to argue that confidential information which has been collected in order to steer DOE's RD\&D

itivities does not lose the character of its confidentiality irely because it is the object of a DOE contract. However, although skilled legal counsel may succeed in sustaining DOE's position in court, the fact that litigation would be necessary to protect valued information and technological evaluations is a factor which may inhibit private sector participation in DOE's planning activities. ${ }^{26}$

While a proposed joint industry-government RD\&D planning panel may not itself be an "agency," as defined in subsection (e) of the Act, the product of its efforts, submitted to the agency itself, can be protected only by a successful argument that it fell within the intra-agency memorandum exception. 27 Once again, this would involve protracted litigation with uncertain chances for success-given the attitude of the federal courts in applying FOIA.

While. FOIA gives the public access to printed material, the open meeting provisions of the Government in the sunshine Act serve as a companion statute by giving the public the right to sit in on the oral deliberations of an agency. In a manner similar to FOIA, the "open meetings" portion of the sunshine Act may have the effect of dampening the enthusiasm of a private entity which submits proprietary information or data to ERDA. That portion of the Act $^{28}$ requires that most agency meetings be open to the public. It also contains provisions which make it exceedingly difficult for an agency to hold a meeting hind closed doors. Where deliberations are so conducted, 
a complete transcript or electronic recording must be kept and must then be made available to the public. It was anticipated by the framers of the legislation that, given the intentionally burdensome procedures for closing a meeting, almost all agency activity would be conducted in public view. 29 Material might be excised from the transcript under the same "trade secret" exception that applies to FOIA, but only as that exception has been construed by the courts in decisions interpreting that law. Thus, private sector participants in DOE RD\&D planning programs once again have some cause to fear that information which they would rather keep from the reach of competitors may not be so protected.

When contemplating the possibility of involving representatives of the private sector in a formalized RD\&D planning process, one must recognize the additional effect of the Federal Advisory Committee Act on the ability of government to convince industry of the benefits of making a contribution. Enacted on October 6, 1972, FACA has broad application and contains stringent disclosure provisions which may well discourage participation in RDED planning by any corporation which is concerned with keeping its ideas and developmental successes confidential. The Act is designed to accomplish the dual primary purposes of:

- Eliminating non-productive advisory panels, by mandating review by Congress and the President, by setting limits on the salaries of members and by establishing two-year limits on the "life" of a committee; and

- Regulating the activity of advisory committees. be open. $30 \frac{\text { FACA mandates that meetings of advisory committees }}{\text { It also renders the research, results of studies, }}$ 
and other data compiled by an advisory panel available to public scrutiny. This provision-perhaps more than any other-can therefore be seen as having the effect on private parties of raising a caveat to possible disclosure of information regarding new technologies. An advisory committee can close its doors to the public only by ensuring the availability nf a transcript.

FACA not only combines the features of FOIA and the unshine Act, which serve to inhibit the flow of information from the private sector to government agencies, but also is directly aimed at the type of advisory board which is contemplated in the present study. As one court has noted, the very purpose of FACA is "to open to public scrutiny the manner in which government agencies obtain advice from private individuals. . . " 31

Moreover, there is nothing that an advisory committee can do to prevent disclosure of confidential information to its own participants. Yet, some of these participants may be the very persons to whom it is most feared disclosure would be made. Thus, the problem of confidentiality draws the viability of advisory committees as a mechanism for joint RD\&D planning into question in those contexts where fear of disclosure is most pronounced.

Although private sector cooperation is an expressed goal of the DOE, that goal may well prove difficult to achieve. The restructuring of the energy administrative process will not. solve the fundamental problem that the risk of public disclosure of information by the private sector will continue to serve as a disincentive for private industry to aid'in the development of energy RD\&D policies and programs. Even a comprehensive regulation, explicitly rotecting from disclosure all information given DOE in 


\section{APPENDIX}

confidence, can only partially remove that disincentive.

NOTES

1. Telephone interview with G. Edwin Brown, Jr., a leading atomic energy consultant.

2. Telephone interview with Richard Begley, Director of Power Systems R\&D Research and Development Center, Westinghouse Electric Corp.

3. 5 U.S.C. $\$ 552$.

4. Pub. L. No. 94-409, 90 stat. 1241 (Sept. 13, 1976).

5. 5 U.S.C. App. I $\$ \S 1$ et seq. (1972).

6. Telephone interview with Richard Begley, supra note 2.

7. 5 U.S.C. $\$ 552(b)(4)$.

8. 5 U.S.C. $\$ 552(\mathrm{~b})(9)$.

9. See, e.g., National Parks and Conservation Association v. Morton, 498 F.2d 765 (D.C. Cir. 1974.).

10. See Washington Research Project, Inc. v. Department of Health, Education $\&$ Welfare, 504 F.2d 238 (D.C. Cir. 1974), cert. denied, 421 U.S. 963 (1975).

11. Telephone interview with a staff member, Office of the General Counsel, ERDA.

12. Charles River Park " $A$ ", Inc. v. Department of Housing and Urban Development, 519 F.2d 935, 942 (D.C. Cir. 1975).

13. Note, "Protection from Government Disclosure-The Reverse-FOIA Suit," 1976 Duke L.J. 330, 340, cited with approval in Westinghouse Electric Corp. v. Schlesinger, 542 F.2d 1190, 1197-98, n. 13 (4th Cir. 1976). See also Note, "Reverse Freedom of Information Act Suits: Confidential Information in Search of Protection," 70 Northwestern L. Rev. 995 (1976) ; Project, "Government Information and The Rights of Citizens," 73 Mich. L. Rev. 971 (1975). 
14. 42 U.S.C. $\$ \$ 5901$ et seg. (1974).

15. 42 U.S.C. $\$ 5916$ (1.976 supp.).

16. 42 U.S.C. $\$ \$ 5801$ et. seq. (1974).

17. 42 U.S.C. $\$ \$ 5817$ (d) (1976 supp.).

18. 42 U.S.C. $\$ \$ 5817$ (e) (1976 supp.).

19. DOE also has considerable power to acquire technical information from the private energy industry under 15 U.s.C. $\$ \$ 772(c),(e), 791(a)$.

20. 41 C.F.R. Part 9-7.

21. 40 Fed. Reg. 48363-48381 (1975).

22. Telephone interview with a staff member, Office of the General Counsel, ERDA.

23. Metropolitan Life Insurance Co. V. Usery, 426 F. Supp. 150, 170 (D.D.C. 1976). Note that the scope of 18 U.S.C. $\$ 1905$ as applied under exemption (b) (3) of the Act is now no greater than the scope of exemption (b) (4) of the Act. $426 \mathrm{~F}$. Supp. at 158, n. 15. Therefore, information not exempt under (b) (4) cannot be deemed exempted by the application of $\$ 1905$ under (b) (3).

24. Id., 426 F. Supp. at 170.

25. Telephone interview, supra note 11 .

26. Telephone interview with James Nelson, Office of the General Counsel, EPA.

27. 5 U.S.C: $\$ 552(b)(5)$.

28. 5 U.S.C. $\$ 552(b)$.

29. H.R. Rpt. No. $94-880,1976$ U.S.C. Cong. \& Admin. News 2183 et 'seq. In practice, since the Sunshine Act is directed at agency meetings, rather than documentary information, the Act may be more applicable to regulatory agencies, while sponsoring research bodies are more concerned with the impact of FOIA. No such distinction is explicitly made by law, however. 1976 U.S.C. Cong. \& Admin. News at 2185. 


\section{APPENDIX}

30. 5 U.S.C. App. I, \$ 10(a)(1).

31. Food Chemical News, Inc. v. Davis, 378 F. Supp. 1048, 1051 (D.D.C. 1974). 
THE ACQUISITION AND PROTECTION OF PROPRIETARY INFORMATION

\begin{abstract}
DOE presently has statutory authority to acquire information, including trade secrets, on all energy resources and technology. However, the threat of disclosure of valuable proprietary information presently inhibits the private sector's willingness to cooperate fully by providing DOE with such information in joint RD\&D planning. RECOMMENDED: A uniform codification of federal policy with regard to trade secrets communicated to the government, or at least to energy-related agencies, is required. Such a statutory scheme should define trade secrets, prohibit their public disclosure and provide civil sanctions for such disclosure.
\end{abstract}

The preservation of technology and commercial information by the law of trade secrets is a judicially created alternative to the patent and copyright laws. 1 Existence of a trade secret ${ }^{2}$ gives rise to a property right which affords a competitor an advantage not available to others. Like the owner of a patent or copyright, the possessor of a trade secret-whether a formula, a pattern, a device or merely a compilation of data-may transfer this information to others or, through appropriate legal action, prevent its unauthorized use or disclosure. 3 .

Federal agencies have taken a variety of approaches to the acquisition and protection of private parties' trade secrets. When acting within the statutory scope of its authority, agency's power to acquire information is "no longer signifiitly affected by [its] confidentiality." 4 Congress, however, has failed to provide many remedies for trade secret violations. The importance of trade secret protection to successful RD\&D planning is obvious. If DOE is to avoid expending its resources repeating the work that the private 
sector has already undertaken, then it must be knowledgeable of the activities of those firms which are at the leading edge of the developing technology. However, these are precisely the firms which are likely to possess trade secrets in the form of technical information which is not yet ready for patent or copyright protection. There can be no doubt that some form of protection for these secrets is needed if the private sector is to be encouraged to divulge them to DOE This becomes increasingly true' as the secret seems closer to translation into a commercial product. Yet, it is precisely DOE's desire to be able to anticipate commercial realities so that it may more effectively accommodate them in its RD\&D planning.

In focusing upon this problem, it is necessary to examine the judicially created common law which has given definition to the concept of trade secret, as well as the recently developing federal legislative activity. Critical to the present examination, of course, is the protection that representatives of industry-competitors-are afforded when they are asked or expected to reveal sensitive market information, research plans or data.

In determining whether information constitutes a trade secret, six factors to be considered are:

- The extent to which the information is known outside of the firm;

- The extent to which it is known by employees and others involved in the firm;

- The extent of measures the firm takes to guard the secrecy of the information;

- The value of the information to the firm and to its competitors; 
- The amount of effort or money expended in developing the information;

- The ease or difficulty with which the information could be properly acquired or duplicated by others. 5

Since secrecy is a necessary element of a trade cecret, once it is effectively disclosed, the original ussessor loses its property right, and the information enters .he public domain. Of course, it is not required that only the proprietor of a business know a trade secret. All employees involved in its use, as well as those independently licensed to use-but not disclose-it, may know a trade secret. ${ }^{6}$ On these points, most courts are uniform. The law is, unfortunately, far less defined with regard to whether a possessor of a trade secret loses his property right upon its disclosure in the course of dealing with a federal administrative agency. Although there appears to be no hard precedent answering this question, a negative answer may be inferred from certain administrative decisions. 7

Merely because the owner of a trade secret is compelled to communicate it to a federal agency, it cannot be said that it has failed to take such measures as are reasonable to protect its secrecy. The owner itself, however, must continue to treat such communicated information as a trade secret in which it maintains a proprietary interest. A restrictive marking or legend on reports, prints or drawings which contain trade secrets is frequently utilized to confirm that the government is intended to be entitled to take only limited rights in the confidential data. 8

Judicial recognition of the legal import of such restrictive markings, however, has been limited at best. 
In International Engineering co. v. Richardson, ${ }^{9}$ for example, a federal district court concluded that the striking of a restrictive legend for data, in which an Air Force contractor claimed a property interest, together with. its subsequent communication to the contractor's competitors, constituted "an adjudication of the contractor's proprietary interest by the contracting officer." 10 It therefore determined that the procedural due process requirements of adequate notice and a full hearing were appropriate. The court cited no direct authority for its conclusion, however, and its holding was subsequently reversed on jurisdictional grounds.

Judicial allowance of recovery against the federal government for misappropriation of a trade secret also recognizes that the status of the information as a trade secret does not terminate upon its communication to a federal agency. ${ }^{11}$ The owner retains its property rights in the trade secret, including its right to sue for wrongful disclosure and misuse of the secret. Trade secret status may, however, be terminated if a federal agency discloses the secret information to third parties, or if the owner and agency agree to do so.

It may be possible to obtain relief in the federal courts for a federal employee's improper disclosure of a trade secret, where the action has a contractual basis ${ }^{12}$ or where an action under the Federal Tort claims Act ${ }^{13}$ is appropriate. The relative value of a judicial remedy-damages or an injunctionin satisfying private participants in joint RD\&D planning must be questioned, however. Only an implied contractual basis for relief presently exists. Moreover, the possibility of recovery for wrongful disclosure of trade secrets divulged during a DOE joint planning session is untested.

Agency employees who wrongfully divulge trade secrets may be subject to mild criminal sanctions. 14 The 
federal statute making such disclosure a misdemeanor provides for a maximum fine of $\$ 1000$ or imprisonment not exceeding one year, or both. A federal employee found guilty of such a criminal violation must also be terminated. However, this statute appears to provide an ineffective deterrent and, though i't has been in effect for almost 30 years, it has yet to be applied in a reported case.

The Congressional mandate to DOE to protect items it identifies as trade secrets ${ }^{15}$ may be of little solace to one providing confidential information to that Agency. Rather, DOE's authorization even to acquire such confidential information merely illustrates that, once such data enters the federal regulatory system, the opportunities for its disclosure abound. The leaking of trade secret information by an employee of a federal agency is certainly of concern to private industry participants in joint RD\&D planning. However, perhaps of even greater concern to a firm providing DOE with confidential, proprietary information, in the course of joint RD\&D planning is the possibility of a DOE employee's leaving the federal government to go to work for a competitor in the energy field.

In the private sector, trade secret litigation frequently arises from the employer-employee relationship. The most important aspect of this employment relationship is that it is a fiduciary one. ${ }^{16}$ An employee may not divulge or use trade secrets of his employer while still in his employ. 17 Not only does this duty of loyalty extend beyond the term of employment, ${ }^{18}$ but frequently the employment contract of a key employee-whether manager, inventor or salesman-may contain a "restrictive covenant" clause preventing the employee from seeking employment with a competitor of his employer's for a fixed period and over a specific geographic region. Such clauses, then reasonable, may be enforceable against both the former 
employee and his new employer through an action for injunctive relief or damages, or both. 19

No safeguards against a former DOE' employee's taking confidential information to his new employer presently exist. Present criminal sanctions for disclosure of confidential information apply only to federal employees, not former employees. 20 Nor may any protection against such an occurrenc be possible, since the practicality of enforcement of any civi or criminal statutes extending to former government employees is problematic at best. Nor would a restrictive covenant for DOE employees, analogous to the noncompetition clause utilized in the private sector, seem to be an appropriate remedial device. To bar DOE employees from seeking future employment in energyrelated industries would certainly limit the number of individuals willing to seek employment with that Department.

Because the statutory protections against DOE's disclosure of trade secrets are so thin, and because the availability of a common law remedy for unauthroized disclosure is uncertain-and its pursuit quite costly-there remains the problem of creating a device to reassure the private sector that it will not be risking financial loss if it discusses its trade secrets with DOE. A partial solution for this problem may be the enactment of legislation providing that, where DOE wrongfully uses or discloses trade secrets in violation of a valid restriction imposed by the owner, the owner's exclusive remedy is to sue the United States for damages. ${ }^{21}$ such remedial legislation, however, will not resolve the problem of disclosure by a former DOE employee. An extension of present criminal sanctions to include former federal employees, as well as a strengthening of the punitive measures involved, may serve as some deterrent against disclosure, but the problems of imposing severe criminal sanctions for this type of activity will remai 
Thus, it may be necessary to create some form of statutory civil sanction for wrongful disclosure-either in the form of a civil penalty or by way of a new cause of action.

\section{NOTES}

E. Kintner \& J. Lahr, An Intellectual Property Law Primer 117 (1975).

2. The most comprehensive and commonly accepted definition of a trade secret is that found in $\$ 757$, Comment $b$, of the Restatement of Torts (1939):

any formula, pattern, device or compilation of information which is used in one's business, and which gives him an opportunity to obtain an advantage over competitors who do not know or use it. It may be a formula for a chemical compound, a process of manufacturing, treating or preserving materials, a pattern for a machine or other device, or a list of customers.

3. R. Milgrim, Trade Secrets $\$ 1.01$ (1977).

4. Gellhorn, "Protecting Trade Secrets in the Administrative Forum," P.I.I., Protecting \& Profiting from Trade Secrets 183 (R. Milgrim 1975).

5. Restatement of Torts $\$ 757$, Comment b (1939).

6. Id.

7. See generally, Kostos, "Unauthorized Use of the Technical Data in Government contracts: Remedies of the Data Owner," 6 B.C. Ind. \& Com. I. Rev. 753 (1965).

8. See, e.g., International Engineering Co. v: Richardson, 367 F. Supp. 640 (D.D.C. 1973), rev'd, 512 F.2d 573 (D.C. Cir. 1975), cert. denied, 423 U.S. $1048(1976)$ : Kostos, supra, at 753.

9. See note 8 supra.

10. 367 F. Supp. at 654 . 


\section{APPENDIX}

11. Pabloc Co. v. United States, 137 U.S.P.Q. 224 (Ct. C1. 1963).

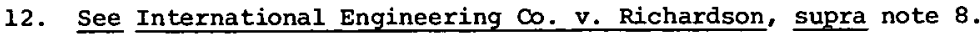

13. 28 U.S.C. $\$ 2674$.

14. 18 U.S.C. $\$ 1905$.

15. 42 U.S.C. $\$ 5916$.

16. See, e.g., Olschewski v. Hudson, 87 Cal. App. 282, 262 P. 43, 44 (1927) (1aundry route employee); Town \& Country Houses \& Homes Services, Inc. v. Evans, 150 Conn. 314, 189 A.2d 390, 392 (1963); B.F. Goodrich Co. v. Wohlgemuth, 117 Ohio App. 493, 192 N.E.2d 99 , 105 (1963). But see American Stay Co. V. Delaney, 211 Mass. 229, 97 N.E. 911, $913(1912)$ (bare employer-employee relationship is not a fiduciary one).

17. See, e.g., Fidelity Appraisal Co. v. Federal Appraisal Co., 217 Cal. 307, 18 P.2d 950, 954 (1933); Cameron Machinery Co. v. Samuel Langston Co., 115 A. 212, 214-15 (N.J. Ch. 1921).

18.' Byrne v. Barrett, 268 N.Y. 199, 197 N.E. 217 (1935) (duty flowing from relationship is absolute and continues after termination of employment).

19. See Milgrim, supra note 3 , at $\$ 3.05[1]$, at 3-67 to 3-84.

20. See 18 U.S.C. $\$ 1905$. See also Kintner \& Lahr, supra note 1 .

21. Such a remedial statute was the Foreign Assistance Act of 1948, Pub. I. 80-472, 62 stat. 137 (April 3, 1948), subsequently repealed. Under that Act, where the Economic Cooperation Administration used or disclosed trade secrets in violation of restrictions imposed by the owner, the exclusive remedy of the owner was to sue the united states for damages in federal district court. The head of that agency had authority to settle such claims before suit. See Kintner \& Lahr, supra note 1 at 219-20. 


\title{
THE PROTECTION OF PATENT RIGHTS
}

\begin{abstract}
Because they are directed at the contractual relationship between DOE and a party offering RD\&D services with respect to a particular project, DOE's patent policies concerning waivers, march-in rights, licensing, and background patents have little, if any, direct effect on the willingness of the private sector to participate in joint planning. Nevertheless, apart from any direct inhibition on such participation, DOE's present policies may induce an attitude in the private sector which is not responsive to the need for cooperation.

RECOMMENDED: DOE should promulgate regulations making waiver, march-in and licensing determinations as predictable as possible, by providing objective standards, where practical, for such decisions. The power of the DOE contracting officer negotiating background patent rights may be expanded to determine the government's need for such on a case-by-case basis.
\end{abstract}

The policy of DOE with respect to patents is governed by $\$ 9$ of the Federal Non-nuclear Energy Research \& Development Act of 1974. ${ }^{1}$ Section 9 resolves the long-standing debate over who should own the rights to inventions developed in the course of government-sponsored RD\&D programs by vesting title to patents in the United States.

In order to achieve DOE's goal of early commercial application of energy discoveries, however, the private sector has deemed it necessary to obtain incentives to venture capital in the area of energy RD\&D. Accordingly, $\$ 9(c)$ of the 1974 Act allows the government to waive its rights in an invention to the ntor. In making a waiver decision, DOE is required to ider four primary objectives:

- Making the benefits of the energy research, develop- . ment, and demonstration program widely available to the public in the shortest practicable time. 
- Promoting the commercial utilization of such inventions.

- Encouraging participation by private persons in the Administration's energy research, development, and demonstration program.

- Fostering competition and preventing undue market concentration or the creation or maintenance of other situations inconsistent with the antitrust laws.

A waiver may be granted at one of two stages in the RD\&D process. Section 9 (d) of the 1974 Act provides for the negotiation of a waiver at the time of contracting. Eleven statutory criteria are provided for DOE's consideration in deciding whether such a waiver would be appropriate. ${ }^{2}$ In addition, the 1974 Act allows waivers to be granted after an invention is identified. In determining whether such a waiver is in the best interests of the United States, eight of the same criteria must be considered. In addition, the secretary is required to consider:

- The extent to which such waiver is a reasonable and necessary incentive to call forth private risk capital for the development and commercialization of the invention; and

- The extent to which the plans, intentions, and ability of the contractor or inventor will obtain expeditious commercialization of such invention. ${ }^{3}$ Notwithstanding the fact that a waiver has been granted, it may be terminated if a contracting inventor has not taken sufficient steps to utilize it in a practical manner within a reasonable time. DOE also may grant a non-exclusive or 
partially exclusive license on an invention, to which the government has waived its rights in other specified situations. ${ }^{4}$ These limitations on the waiver principle are known as "marchin" rights. These rights may also be invoked when the contractor is not commercializing the invention, or the exclusivity of the waiver is determined to tend toward violation of " $=$ antitrust laws. However, in these situations, the governnt's right may not be exercised until four years after the erfective date of the waiver. ${ }^{5}$

DOE's regulations governing waivers follow the general considerations enumerated by the 1974 Act. ${ }^{6}$ When these regulations were first proposed in October, 1975, there was a great deal of skepticism on the part of the private sector as to whether the waiver provisions would constitute a significant exception to the statutory policy of maintaining title to patents in the government. 7 In 1976, however, approximately $40 \%$ of the advance waivers requested wexe, in fact, granted: 8 While a few requests were denied, most of the remaining number are pending decision.

When a waiver is refused or is not sought by a party contracting with DOE, the inventor normally retains a revocable or irrevocable, nonexclusive, paid-up license for practice of the invention. DOE may grant an exclusive or partially exclusive license to a third party, even though the inventor also retains a right to practice it. While a contractor's license to practice an invention may be revoked, the regulations on this point provide:

The contractor's nonexclusive license retained in the invention may be revoked or modified by [DOE] only to the extent necessary to achieve expeditious practical application of the 
APPENDIX

invention pursuant to an . . exclusive

license for the invention. 9

. According to $\$ 9(g)(2)$ of the 1974 Act, an exclusive or partially exclusive license may be granted, only if, after a hearing, it is determined:

- The public interest will best be served by the proposed license, in view of the applicant's intentions, plans, and ability to bring the invention to the point of practical or commercial applications ;

- The desired practical or commercial applications have not been-or are not likely expeditiously to be-achieved, under any nonexclusive license which has been, or may be granted on the invention;

- Exclusive or partially exclusive licensing is a reasonable and necessary incentive to call forth risk capital and expenses to bring the invention to the point of practical or commercial applications; and

- The proposed terms and scope of exclusivity are not substantially greater than necessary to provide the incentive for bringing the invention to the point of practical or commercial applications and to permit the licensee to recoup its costs and a reasonable profit.

An issue paralleling the question of the relative rights of DOE and a contractor in an invention concerns the background patents which the contractor has developed in a specified area of energy technology. Normally, a contractor selected to perform work under a DOE contract has developed a degree of expertise 
in the field to which the contract relates. The patentable results of such research, however, may be necessary to promote DOE's goal of the prompt commercial utilization of such technology. Accordingly, DOE's regulations specify a contract clause which is to be included in DOE contracts exceeding $\$ 250,000.10$ DOE may also require the licensing of background patents to third parties.

In addition to the background patent provision, party contracting with DOE must allow access to its records relating to inventions. Under DOE's stipulated contract provisions, a contracting officer or his authorized representative has the right to review all of the contractor's books, laboratory data and notes, as well as records and documents. 11

DOE regulations concerning waivers, march-in rights, exclusive or non-exclusive licenses, revocable or irrevocable licenses, and background patent rights are obviously of deep concern to potential DOE contractors. Nevertheless, DOE's patent policies may not be invoked until a contractual relationship is established between DOE and a party which is offering RD\&D services with respect to a particular project. For this reason, DOE's patent policies may have little, if any, direct effect on the willingness of the private sector to communicate with DOE concerning the best possible way of utilizing its. resources for RD\&D programs. It is doubtful that DOE's patent policies or regulations alone inhibit a private entity from participating on an advisory board which has the purpose of focusing DOE's activity on feasible commercial ventures.

This conclusion, however, cannot be drawn in the case of legislation that establishes the compulsory licensing of patents held by third parties not in privity with DOE. Such a provision, similar to those contained in the Atomic Energy Act., ${ }^{12}$, 


\section{APPENDIX}

and the clean Air Act, ${ }^{13}$ has been proposed in some quarters. If it were enacted, the private sector would be highly interested in protecting proprietary rights in its patents and other data. Accordingly, there would be a disincentive to any communication with government agencies, such as DOE, which might lead to the loss of exclusive rights in such property. The royalty rights which accompany mandatory licensing are not thought to be sufficient compensation for the commercial development of an invention. ${ }^{14}$

Apart from any direct inhibitions on the communication between DOE and its contractors, DOE's present patent policy may, in certain cases, induce an attitude which is not responsive to the need for cooperation in the achievement of its goals. It is axiomatic that the primary motive of private companies in contracting, or otherwise cooperating, with DOE is desire for profit. However, DOE's patent policies may affect a contractor's perception of its ability to achieve a suitable return on the investment it commits to DOE RD\&D programs. Obviously, a potential contractor's perceptions in this regard will also be the most important consideration in its determination to enter a contractual relationship with DOE. ${ }^{15}$

A DOE contractor often commits a large amount of its own capital to the commercial development of an invention. 16 However, to the extent that uncertainty is introduced into a particular program, a potential contractor's willingness even to engage in planning activities with DOE will be reduced. From the viewpoint of the private sector, the ideal situation would be to vest title to patents, arising out of government sponsored RD\&D programs, in the contractor as a matter of course. Since statutory provisions prevent this, a contractor 
interested in receiving funds from DOE will frequently seek the security offered by a waiver of the government's rights in a patent.

In order to promote private sector participation in DOE RD\&D planning it seems desirable to make waiver, march-in and licensing determinations as predictable as possible. -- ever, DOE's regulations simply follow the statutory provisions the 1974 Act by enumerating factors to be considered by DOE. conceivably, the regulations could be restructured so as to provide a more objective test.

One of the greatest fears which businesses have with regard to transacting with DOE is the provision for the government's acquisiton of the background patents of a contractor. ${ }^{17}$ The private sector obviously fears the loss of investment in prior research, and this provision means that the benefits of such research can be extended to a firm's competitors. Thus, while the background patent provisions are intended to promote a rapid diffusion of technological information, the opposite result may occur in some cases, since some businesses may prefer to protect their investment in prior research by avoiding contact with DOE entirely. This problem is a particularly difficult and emotional one, for which no satisfactory solution can probably be offered. However, a helpful approach may be to expand the power of the ERDA contracting officer negotiating such rights to determine the need of the government for background patents on a case-by-case basis.

\section{NOTES}

1. 42 U.S.C. $\$ 5908$.

The criteria called for in $\$ 9(d)$ are: 


\section{APPENDIX}

(1) the extent to which the participation of the contractor will expedite the attainment of the purposes of the program;

(2) the extent to which a waiver of all or any part of such rights in any or all fields of technology is needed to secure the participation of the particular contractor;

(3) the extent to which the contractor's commercial position may expedite utilization of the research, development, and demonstration program results;

(4) the extent to which the Government has contributed to the field of technology to be funded under the contract;

(5) the purpose and nature of the contract, including

the intended use of the results developed thereunder;

(6) the extent to which the contractor has made or will make substantial investment of financial resources or technology developed at the contractor's private expense which will directly benefit the work to be performed under the contract;

(7) the extent to which the field of technology to be funded under the contract has been developed at the contractor's private expense;

(8) the extent to which the Government intends to further develop to the point of commercial utilization the results of the contract effort;

(9) the extent to which the contract objectives are concerned with the public health, public safety, or public welfare; (10) the likely effect of the waiver on competition and market concentration; and

(11) in the case of a nonprofit educational institution, the extent to which such institution has a technology transfer capability and program, approved by the Administrator as being consistent with the applicable policies of this section.

3. 42 U.S.C. $\$ 5908(e)$.

4. See 41 C.F.R., $\$ 9-9.109-6$ (i) (9).

5. See generally, 42 U.S.C. $\$ 5708(\mathrm{~h})$.

6. See 41 C.F.R. $\$ 9-9.109-1$.

7. See, e.g., P. Sperber, "Government Contracting: Perpetuating the Energy Crisis," 62 A.B.A.J. 1301 (1976). 
8. Confidential telephone interview with ERDA Patent Counsel.

9. 41 C.F.R. $\$ 9-9.107-3(b)$.

10. See 41 C.F.R. $\$ 9-9.107-5(k)(2)$.

11. See 41 C.F.R. $\$ 9-9.107-5(h)$.

12. 42 U.S.C. $\$ 2183$. This section is a limited one which applies only if:

(1) the invention or discovery covered by the patent is of primary importance in the production or utilization of special nuclear material or atomic energy; and

(2) the licensing of such invention or discovery under this section is of primary importance to effectuate the policies and purposes of this Act.

The power it originally delegated to the Atomic Energy Commission was transferred to ERDA by 42 U.S.C. $\$ 5814$ (d). The proposal contemplated here would greatly expand $\$ 2183$ to nonnuclear energy patents.

13. 42 U.S.C. $\$ 1857 \mathrm{~h}-6$.

14. The Patent Policies Affecting ERDA Energy Programs 250; Confidential telephone conversation with ERDA Office of General counsel.

15. See generally, P. Sperber, supra; Public Comments on ERDA Proposed Regulations - Proposed Policies and Procedures, The Patent Policies Affecting ERDA Energy Programs, App. B.4.

16. The Patent Policies Affecting ERDA Energy Programs, App. B.4 at 33-35.

17. The Patent Policies Affecting ERDA Energy Programs, ApP. B.3 at 77-83. 


\title{
ORGANIZATIONAL CONFLICTS OF INTEREST
}

\begin{abstract}
When DOE contracts to obtain advice, the advice it obtains should be objective, trustworthy, and not slanted to promote the aspirations of the advising firm. Moreover, no firm should be allowed to prepare specifications in such a manner that it is given an unfair advantage in later procurement contracting. In recently passed legislation to achieve these objectives, however, Congress may have dictated the result that a firm, which gives advice that results in a benefit to an entire industry by influencing general agency policy, may be barred from all follow-on work in the field. For this reason, the most active and knowledgeable firms in a field may refuse to agree to give preliminary advice to ERDA. RECOMMENDED: DOE's conflict of interest regulations must both promote the attainment of objective advice and avoid unfair advantages in contracting, without discouraging knowledgeable firms from agreeing to render their advice. The regulations must be made clear and permanent so that firms may assess accurately the risks of losing future contract opportunities.
\end{abstract}

Perhaps the most serious legal obstacle to greater private sector participation in DOE's RD\&D planning process arises from the fact that the participating firms are private. For this reason, their individual private interests can never be identical with the public interest. It has therefore been deemed necessary for DOE to avoid those situations in which the purely private interests of a firm with which it is dealing conflict egregiously with the interests of the public.

The term "organizational conflict of interest" refers to the situation where a firm, which has dealings with the federal government, also has other interests-either to its other activities or its relationships with other organizations. which place it in an unsatisfactory or unfavorable position either: 
- From the Government's standpoint in being able to secure impartial, technically sound, objective assistance and advice, or in securing the advantages of adequate competition; or

- From industry's standpoint in that an unfair competitive advantage may accrue to the firm in question. I

The problem of organizational conflicts of interest sis government contracting is not a new one. It has been debated sporadically in Congress over the past 15 years. The House Committee on Government Operations initiated inquiries into these conflicts in 1959, and these inquiries were continued in 1961. In 1962, President Kennedy appointed a committee, headed by Budget Director David E. Bell, to study the problem. The "Bell Report" recommended that each agency develop regulations to govern conflicts of interests. ${ }^{2}$ In 1963 , a House Committee conducted an investigation which has influenced the focus of subsequent regulations governing organizational conflicts of interest. The investigation involved a firm which had been given a contract to prepare specifications for a project and then was permitted to compete for the resulting procurement contract. ${ }^{3}$

An objection can legitimately be raised to any situation which offers a private party the opportunity to draft or affect government contract specifications in a manner which would favor it in later procurement bidding. Obviously, a firm which can affect the preparation of specifications has an unfair competitive advantage in later bidding on actual projects. Prevention of such unfair competitive advantages has, therefore, been a major thrust of the various federal regulations governing organizational conflicts of interest. These regulations were 


\section{APPENDIX}

adopted early by the Defense Department, the National Aeronautics and Space Administration and the former Atomic Energy Commission.

A second goal of regulations dealing with conflicts of interest is to ensure that the government obtains unbiased and reliable advice from those with which it deals. However, in practice, the only type of bias upon which federal agency attention has focused has been that which had a potential for unfair competitive advantage. These situations have primarily involved "follow-on" contracts, which are envisioned to be open for bid as a consequence of planning activities. Thus, for example, if a firm is deemed to be a "sole source" contractor in a particular project, the fact that the firm participated in planning the project generally is regarded as irrelevant since, by definition, no competitor will be adversely affected by this arrangement. ${ }^{4}$ Those who undertake general feasibility studies which do not involve'the preparation of specifications are not prevented by present regulations from bidding on the ultimate product. ${ }^{5}$ Existing regulations can be criticized, however, for overlooking the fact that the mere possibility of a future contract may produce a favorable feasibility study, with conclusions flavored by prospects of that contract.

The practical importance of these regulatory loopholes was recently revealed in the "Bechtel Hearings" before the Subcommittee on Energy Research and Water Resources of the Senate Interior Committee. As a result of these hearings, Senator Abourezk (D. S.D.) concluded that a conflict of interest had existed in the Bechtel contract, but that it had gone unrecognized for several reasons: 
- There was no requirement that conflicts of interest. be disclosed to ERDA's contracting officials in the bidding process.

- This was not a contract where a follow-on procurement was envisioned.

- It was a sole source contract. ${ }^{6}$

us, since the regulations had been aimed primarily at followsituations which pose threats of unfair competitive advantages, the Bechtel contract was not one which was likely to raise questions of organizational conflicts of interest.

The Bechtel Hearings caused Senator Abourezk to sponsor legislation which would address conflict of interest situations. At the same time, ERDA began work on changes in its procúrement regulations. Other bodies also began work on regulations which were to be applicable to all federal agencies.

The ERDA efforts resulted in the promulgation of ERDA-PR Temporary Regulation 35. This regulation includes a disclosure provision which pertains to all "evaluation and technical consulting and management support services." 7 It attempts to rectify the fact that ERDA was not formally receiving information as to possible sources of conflicts of interest among those with whom it dealt. In the case of the AEC, from which ERDA adopted its regulations, such formal channels of information might not have been necessary, due to the small number of firms involved in the field. DOE, in contrast, is less able to rely on informal channels of communication. Therefore, Temporary Regulation 35 requires offerors to provide information on potential conflicts of interest. ${ }^{8}$ The regulation requires the inclusion of a contractual prohibition of certain follow-on work in contract

$r$ certain types of tasks: 
APPENDIX

If the Contractor performs technical consulting or management support services . . ., or similar work, under this contract, it shall be ineligible thereafter to participate in any capacity in Government contractual efforts (solicited or unsolicited) which stem directly from such work, and the contractor agrees not to perform similar work for prospective offerors with respect to any such contractual efforts. 9

Despite the existence of a predecessor to Temporary Regulation 35, Congress chose to enact additional legislation governing organizational conflicts of interest in DOE contracting. This effort was incorporated into PL 95-39, signed into law on June 3, 1977. Like Temporary Regulation 35. the major thrust of PI 95-39 is to provide information to agencies so that they may recognize potential conflicts of interest. 10 It instructs the secretary to require any firm proposing to enter into a contract agreement, or other arrangementwith DOE to provide the secretary with all relevant information bearing on whether that firm has a possible conflict of interest with respect to:

- Being able to render impartial, technically sound, or objective assistance or advice in light of other interests or relationships with other persons; or

- Being given an unfair competitive advantage. 11

The Act, however, gives officials considerable leeway in formulating methods of dealing with organizational conflicts of interest which would be revealed by an offeror: 
[I] he determines that a conflict of interest exists and . . cannot be avoided - . the Administrator may enter into a contract, agreement, or arrangement, if he determines that it is in the best interests of the United States to do so and includes appropriate conditions in such contract, agreement, or arrangement to mitigate such conflict. ${ }^{12}$

Both Temporary Regulation 35 and P.L. 95-39 seem to apply and encompass any possible contractual arrangement designed to help DOE order its funding priorities. Among organizations which currently have contractual relationships with DOE, problems arise in the two provisions, which may tend to discourage further participation in efforts to help DOE set its RD\&D priorities.

The major element common to Temporary Regulation 35 and P.L. 95-39 is a requirement that an offeror provide data so that potential conflict of interest may be determined. Both the legislative and executive branch appear to agree that this was a reasonable means of effectuating the policy ensuring that information provided by the private sector be accurate and reliable. Industry, however, has registered considerable disagreement with this view. One criticism is of the sweeping and undefined nature of the information required. For example, P.L. 95-39 requires the disclosure of "all relevant information bearing on whether that person has a possible conflict of interest. . . in light of other interests or relationships with other persons," while Temporary Regulation 35 requires the offeror to provide a statement which describes, in a 
concise manner, all relevant facts concerning any financial, contractual, organizational, or other interests relating to the work it is to perform, and bearing on whether the offeror has a possible conflict of interest with respect to:

- Being able to render impartial, technically sound, and objective assistance or advice; or

- Being given an unfair competitive advantage. The language of P.L. 95-39 has been condemned as so vague that an offeror would find it nearly impossible to know the scope of information required. One commentator has stated that it is:

both broad and lacking in precision. One anticipated consequence of this fact may well be (1) hyperactive criticism of contractor failures to have pre-disclosed subsequently identifiable conflicts that, with the benefit of hindsight, were "possibly" discernible in the pre-contract stage and (2). if sanctions are to be provided for by the implementing regulations, the unfair imposition of penalties for the nondisclosure of a "possible" conflict that should have been anticipated or perceived by the contractor when competing for the contract. 13 These effects are multiplied by the fact that the scope of many RD\&D planning activities will be uncertain at the time that disclosure would be required. It may, therefore, not always be possible to predict the conflicts of interest which may eventually arise.

Such informational requirements also may present nearly insurmountable problems to large corporations dealing 
with DOE. These corporations may have hundreds of contracts with various government agencies, and many divisions and product lines. It would certainly be difficult for such a firm to certify that no conflicts of interest exist. Any attempt to gather all the required information would be extremely time consuming and expensive. ${ }^{14}$ Thus, the requirement nay make it less likely that such a corporation will be willing to participate in RD\&D planning activities. Planning studies, of course, tend to be relatively small in dollar amounts as compared to RD\&D contracts themselves. Indeed, for a major corporation, the effort to gather this information may well exceed the potential profit to be realized from a planning contract. Thus, a corporation which is willing to gather the necessary information for an RD\&D contract may be unwilling to do so in order to participate in RD\&D planning.

Moreover, the exclusion of follow-on work for those types of contracts covered by Temporary Regulation 35 may deter the most qualified firms from entering into covered contracts. 15 obviously, few firms will be enthusiastic about participating in planning activities where the result is to eliminate future RD\&D work in that field. Most firms have little interest in "one shot" contracts, and much prefer to sustain continuing efforts or product lines. Moreover, prohibitions on follow-on contracts are most likely to deter initial advisory work by those firms having the most practical expertise in a field, since it is these firms which are most likely to be concerned that they will be cut off from subsequent work of a more substantive nature.

The regulations, as they existed some time prior to the promulgation of Temporary Regulation 35 avoided this result by narrowly defining the scope of prohibitions on follow-on work 


\section{APPENDIX}

to those to be used in procurement. ${ }^{16}$ General feasibility studies were not deemed to result in a prohibition in follow-on work. Temporary Regulation 35 is less explicit, however. It prohibits follow-on work which "stem[s] directly from" previous work. No guidance is given as to what work may be considered to "stem directly" from advisory planning participation. Without more explicit guidance some firms will certainly be unwilling to undertake advisory work for fear that a later sweeping interpretation of this phrase may cut them off from large areas of RD\&D involvement.

In the final analysis, it must be recognized that there are two competing-and probably irreconcilable-policy factors at work, affecting any effort to involve the private sector in ERDA's RD\&D planning. On the one hand, there can be little doubt that, when the government contracts to obtain advice, that advice should, to the maximum extent possible, be objective and trustworthy. It certainly should not be slanted to promote the aspirations of the advising firm. Nor is there any doubt that a firm should not be allowed to prepare specifications in such a manner that it is given an unfair advantage in later procurement contracting. If, however, these concepts are carried to extremes, so that giving advice, which results in benefiting an entire industry by influencing DOE policy, has the effect of the advising firm's being barred from follow-on work in an entire field, the firms most active and knowledgeable in the field will almost certainly refuse to contract to give such preliminary advice.

Temporary Regulation 35, therefore, it seems, is in need of further revision to take these two policy factors into account. Whatever balance is struck, the rules must be clear and permanent, since uncertainty as to the scope of later exclusions is perhaps the greatest deterrent to private sector 
participation in DOE's planning activities. Ambiguity as to the breach of conflict of interest prohibitions makes it impossible for firms to estimate accurately the tradeoffs involved in undertaking a present advisory role for DOE and risking the loss of future RD\&D contract opportunities.

\section{NOTES}

1. 41 C.F.R. $\$ 9-1.5405$.

2. U.S. Bureau of the Budget, Report to the President of Government Contracting for Research and Development, S. Doc. No. 94, 87th Cong., 2d Sess. (1962).

3. House Comm. on Government Operations, Avoiding Conflicts of Interest in Defense Contracting and Employment, H.R. Rep. No. 917, 88th Cong., lst Sess. (1963).

4. See, e.g., 41 C.F.R. $\$ 9-1.5407$ (b).

5. See, e.g., 41 C.F.R. $\$ 9-1.5407(c)$.

6. Statement of Sen. Abourezk before the Senate Committee on Banking, Housing and Urban Affairs 8-9 (May 19, 1977).

7. 41 C.F.R. $\$ 9-1.5406$ (d). Earlier in the Regulation, those terms were defined:

(b) The term "evaluation services" means any work or effort involving the independent study of a particular technology, process, or product which entails the assessment, appraisal, or survey of such technology, process, or product.

(c) The term "technical consulting and management support services" means any work or effort to provide internal assistance to any ERDA program division or other organizational component in the formulation or administration of its programs or projects, which normally necessitates that the contractor be given access to internal ERDA information. Such services typically include assistance in the preparation of program plans; evaluation, monitoring 
or review of contractors' activities or proposals submitted by prospective contractors; preparation of preliminary designs, specifications, or statements of work; the making of recommendations, or the rendering of an opinion or advice regarding any technical problem, issue, or question.

41 C.F.R. $\$ 9-1.5405$. It therefore seems likely that any formal agreement to participate in joint planning of DOE's RD\&D activities is subject to the Regulation.

8. 41 C.F.R. $\$ 9-1.5406$ (d).

9. 41 C.F.R. $\$ 7.5006-40$. The prohibition provision adds:

The term "technical consulting and management support service" means any work or effort to provide internal assistance to any ERDA program division or other organizational component in the formulation or administration of its programs or projects which normally necessitates that the contractor be given access to internal ERDA information. Such services typically include assistance in the preparation of program plans, evaluation, monitoring or review of contractors' activities or proposals submitted by prospective contractors; preparation of preliminary designs, specifications, or statements of work; the making of recommendations, or the rendering of an opinion or advice regarding any technical problem, issue, or question.

10. Telephone interview with Chuck Ludlam, Counsel to Sen. Abourezk (D. S.D.).

11. P.L. 95-39, \$ 401 (amending 42 U.S.C. $\$ 4901$ ).

12. P.L. $95-39, \$ 401$.

13. Crowell, "The Organizational Conflict of Interest-What is it and Why is it? What Should be Considered an Unfair Competitive Advantage?" presented at the ABA National Institutes, at 16-17 (1977).

14. Confidential interview with an executive of a major aerospace firm currently holding a number of DOE contracts.

15. Crowel1, supra note 13, at 19-20. This view was expressed in a conversation with Roger D. Spencer, Director of Government and External Affairs, Glass Division, P.P.G. Industries. A staff member of the 
Office of the General Counsel, ERDA, confirmed that a number of large firms have expressed concern about the loss of follow-on work and that for this reason such firms may be unwilling to engage in small preliminary contracts.

16. 41 C.F.R. $\$ 9-1.5407$ (c). See also Hayes International Corp. v. McLucas, 509 F.2d 547 (5th Cir. 1975). 


\section{THE IMPACT OF ANTITRUST CONSIDERATIONS}

The range of potentially anticompetitive activities that could take place in the context of the joint planning of DOE RD\&D makes it impossible to guarantee that industry participation will not result in, at least, allegations of an antitrust violation. Despite the difficulties of proving an antitrust violation, the cost of such litigation itself and the vagaries of the federal judiciary, with the threat of treble damages as a consequence, persuades many in the private sector to take a conservative stance to such joint RD\&D planning. RECOMMENDED: In the event that it is determined that individual planning sessions with each representative of a particular industry are not practicable, an anticompetitive review process for joint RD\&D sessions may afford some protection to participants and open lines of communication.

The threat of antitrust liability is frequently cited as a deterrent to participation by private industry in the planning of DOE sponsored RD\&D programs. ${ }^{1}$ Careful examination of the antitrust laws themselves, ${ }^{2}$ as they apply to the joint planning situation, does not, however, produce a satisfactory explanation of the reluctance of certain firms to "sit down in one room" with representatives of their competitors and discuss their common business affairs.

Section 1 of the Sherman Act proscribes, "[e]very contract, combination . . . or conspiracy, in restraint of trade or commerce among the several states, or with foreign nations. . . ." 3 section 2 of that Act is the anti-monopoly section. ${ }^{4}$ Section 73 of the Wilson Tariff Act, enacted four years after the Sherman Act, is virtually identical to section 1 of that Act, except that one of the parties to the forbidden conspiracy must be engaged, as agent or principal, in importing goods into the United States. 5

The draftsmen of the Sherman Act prohibitions intended a broad sweep to the Act. The construction of the 
terms "restraint of trade" and "monopolization" was left to the courts. The federal judiciary's and executive's predominant inclination toward laissez-faire economics in the late 19 th and early 20 th centuries, however, gave rise to pressure for a more specific statute. The result was the clayton Act, enacted in 1914, which prohibited specific, discriminatory trade practices that "may have an anticompetitive effect." In an attempt to overcome government reluctance to enforce the antitrust laws, the Congress also greatly enlarged, in $\$ 4$ of the clayton Act, the rights of a private party to sue for damages resulting from violations of the antitrust laws. The Act provides private parties with the right to recover treble damages plus the costs of suit, including a reasonable attorney's fee. 6

Concern for the plight of the small businessman amidst the ravages of the Depression years led to the enactment of the Robinson-Patman Act in 1936. This Act, amending section 2 of the Clayton Act, was intended to increase the protection of small retailers against price discrimination presented by large multi-unit, "chain store" operators.

The Federal Trade Commission Act, which was passed in 1914, was enacted for much the same reason as the clayton Act: the feeling that the Sherman Act was inadequate to deal with specific trade practices. However, unlike the clayton Act, the Federal Trade Commission Act was even broader in scope than the Sherman Act. Section 5 prohibited "unfair methods of competition in commerce." 7 The wheeler-Lea amendments, added in 1938, broadened section 5 to include a prohibition against unfair or deceptive acts or practices in commerce." 8 As a further impetus to curing trade abuses, the initial adjudication 


\section{APPENDIX}

of the legality of such abuses was left, not to the courts, but to the newly created Federal Trade Commission. The Commission was given the power to issue injunctions in the form of cease and desist orders. Violation of cease and desist orders was made punishable by civil penalties. No provision was made, however, for a private cause of action, similar to that created by the clayton Act, under the Federal Trade Commission Act.

Assuming that industry representatives assisting DOE in joint planning efforts do not intend to violate the antitrust laws, the threshold issue here becomes whether joint RD\&D planning discussions themselves can violate the antitrust laws. The Clayton Act and the Robinson-Patman Act appear to be of minimal relevance to this issue. Those Acts require, as jurisdictional elements, actual sales or acquisitions. Thus, any agreement reached at a joint planning session to recommend certain RD\&D activities would be of little importance in ascertaining whether one of these Acts had been violated, compared to the circumstances actually surrounding the sale or acquisition. This is not to say that the fact of a joint planning session is utterly irrelevant to an alleged clayton Act or Robinson-Patman Act violation. Rather, the point here is that other facts will be far more important to any effort to substantiate such allegations.

Overt acts are also required to prove monopolization or an attempt to monopolize under $\$ 2$ of the Sherman Act. ${ }^{9}$ The prohibitions, in $\$ 1$, of a conspixacy to restrain trade and, in $\$ 2$, of a conspiracy to monopolize do not, however, require any overt act other than the act of conspiracy. ${ }^{10}$ consequently, an industry representative attending a joint planning session, with no intent to engage his corporation in any later overt acts arising out of the discussion, can still be charged with 
a violation of the conspiracy prohibitions of $\$ \$ 1$ or 2 of the Sherman Act. Thus, a violation of $\$ S 1$ or 2 is a theoretically possible result of a firm's participation in a DOE RD\&D planning session.

Section 1 of the Sherman Act forbids conspiracies "in restraint of trade," a phrase that is obviously impossible to define precisely. In the early cases, the courts looked the common law concept of restraint of trade for guidance. I soon arrived at the conclusion that the statute prohibited only "unreasonable" restraints of trade. 11 As later explained by Justice Brandeis in Chicago Board of Trade v. United States: ${ }^{12}$

Every agreement concerning trade, every regulation of trade, restrains. To bind, to restrain, is of their very essence. The true test of legality is whether the restraint imposed is such as merely regulates and perhaps thereby promotes competition or whether it is such as may suppress or even destroy competition. 13

The courts have unfortunately been able to add little else to the concept of restraint of trade over the years. Consequently, every imaginable restraint on economic activity, upon a finding that it is unreasonable, is a potential violation of section 1 . The types of restraints that have been the subject of litigation thus far may, however, be categorized into certain broad groups :

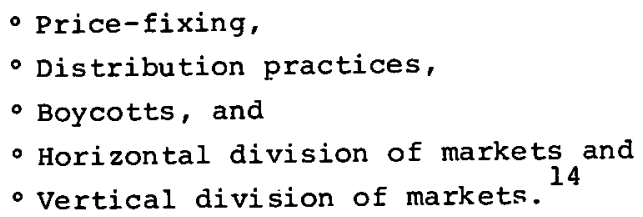


Although competitors at a joint RD\&D planning session could reach a prohibited agreement as to existing products or markets where the agreement is ancillary or even irrelevant to the issues raised by DOE, that situation needs little reference here. A DOE planning session is neither the only, nor the best, vehicle for reaching such agreements if industry members desire them. Since DOE is primarily interested in research, development and demonstration of new products and processes, it should be assumed that the potenti restraints would arise in that area.

Perhaps the most celebrated instance of an alleged restraint of trade involving $R \& D$ is United States $v$. Automobile Manufacturers Ass'n. ${ }^{15}$ There, the four major automobile manufacturers and their trade association were charged with violating $\S 1$ by conspiring to eliminate competition in the research, development, manufacture and installation of motor vehcile air pollution control equipment, and in the purchase from others of patents and patent rights covering such equipment. The defendants had entered into a joint venture agreement as a combined effort to develop pollution control devices. The agreement contained restrictive cross-licensing provisions for any patents obtained. The case was ultimately settled by a consent decree and thus the issues were never adjudicated.

Although the case is often cited as evidence of the potential for antitrust liability in joint R\&D ventures, it must be kept in perspective. The defendants were not charged with violating $\$ 1$ by entering into the agreement to engage in joint research. The crux of the charge was the alleged agreement by the defendants to delay the implementation of 
pollution control devices. It must further be recognized that even that agreement is not obviously a restraint of trade. This point was recognized in the later opinion by the court approving the consent decree and dismissing petitions for intervention filed by parties seeking to assert treble damage claims. The court noted:

Those objecting have all assumed that the Government would win the action if it were brought to trial. But the Government's case is based upon a novel and unadjudicated theory. Knowledgeable people disagree as to the final result. 16

The point here is that it is quite difficult to prove that an agreement relating to a product or process which is not yet developed, and the market potential of which may be nil, somehow restrains trade. These difficulties are compounded in the situation presented by an agreement arrived at in a joint planning session which would likely be informal and would have none of the formal trappings of the written joint venture agreement signed by all the parties in the Automakers case. Nevertheless, the difficulties of proving an antitrust violation do not mean that no antitrust problems exist. Certainly such problems may be posed even if the informal agreements reached in a DOE-sponsored planning session are unlikely to be held in restraint of trade. These problems may derive from the possibility that the Justice Department or a third party may decide to argue that a violation has arisen out of a planning session, and to file a complaint against its participants. The potentially disastrous impact of antitrust litigation on any corporation is enough to persuade corporate counsel to adopt a conservative stance. ${ }^{17}$ The time 
and costs involved in defending an antitrust suit, even disregarding the possibility of a treble damage recovery, are frequently staggering.

A second source of antitrust problems for joint planning participants is derived from the concept of "conscious parallelism." Parallel business activity by competitors, which is, in any way, related to matters discussed at a joint planining session may arguably be circumstantial evidence sufficient to sustain a jury finding of conspiracy. This concept was recognized by the supreme Court in 1939.18 Although the Court in later cases had made clear that the conscious parallelism concept has not read conspiracy out of the Sherman Act entirely, ${ }^{19}$ it nevertheless constitutes another area where the mere presence of competitors at a joint meeting can be later linked to seemingly innocent, independent business activity to form the basis for an antitrust complaint. Indeed, even though no agreement is reached at a joint planning session, the mere presence of industry representatives at a meeting can support an allegation that some agreement was reached if later market developments suggest a violation. The lure of treble damages has undoubtedly given rise to complaints based on a great deal less.

The possibility of prosecution under the Federal Trade Commission Act is even greater. Section 5 of that Act forbids "unfair" methods of competition. The clayton Act standard of liability - that an act "may be to substantially lessen competition or tend to create a monopoly"-was enacted. to prohibit practices which might not amount to actual restraints of trade, so that they could be arrested in their incipiency. This was considered to be an improvement over the Sherman Act standard. However, the Federal Trade Commission, with its broad investigative 
powers, is not required to fulfill even the clayton Act standard. 20 The standards for an FTC Act $\$ 5$ case are even more nebulous than the sherman Act, and liability is simply decided on a case-by-case basis. Although the courts are the final arbiters of liability, great weight is usually given to Commission findings.

Finally, it may be argued that those parts of the rivate sector in which antitrust concerns are most deeply felt are frequently those which are already engaged in practices that may be questioned under the antitrust laws. These firms may well be reluctant to participate in any further activities which can spotlight their questionable practices, simply out of fear of litigation over them. Thus, cooperation with competitors in DOE planning can be thought to raise the inference of cooperation in other contexts. There are certainly some firms, industries and trade associations which would feel more comfortable if such inferences were, neither drawn nor examined.

The risks inherent in making decisions regarding the antitrust laws are magnified by the often inconsistent and vague decisions rendered by the federal courts. The economic and political philosophies of the individual judges seem at least as important to understanding those decisions as is legal precedent. 21 Moreover, the practical reality of antitrust litigation is that it is extremely difficult to find an impartial jury where the defendant is a large oil company, or worse, a group of large oil companies.

The number of possible scenarios that could take place at, after, or in conjunction with a joint planning session makes it impossible to guarantee, given the possible consequences, that it is safe for industry representatives to meet and plan 
RD\&D programs. Indeed, a number of bills pending in Congress would require DOE to investigate any possible anticompetitive effects resulting from the award of a contract-including, presumably, one designed to steer RD\&D efforts. 22 Increases in market concentration, decisions in competition and creation of market entry barriers are among the effects to be reviewed. Although the concept of such an antitrust review prior to the award of a contract may prove to be sound and workable, it has seemingly little relevance to joint planning sessions. Once a contract to engage in RD\&D work is awarded. any anticompetitive effects arguably resulting therefrom are capable of some degree of analysis. In evaluating agreements to engage in RD\&D planning, however, anticompetitive review would be far more hypothetical, since it would not be clear what the results of the planning session would be. In a sense, the anticompetitive review would be undertaken simply to determine who should be present at the planning session. It would seemingly be too early in the process to determine with any degree of accuracy what the anticompetitive effects might ultimately be.

Three possible alternatives seem to exist to avoid the antitrust problems of joint RD\&D planning. The first is to have an attorney from the Antitrust Division of the Justice Department present at all meetings. The second is to hold only public hearings. The third is to meet with industry representatives only individually. Of these, only the last seems to be certain of avoiding antitrust problems entirely. However, this result is achieved at the cost of eliminating the interaction and debate which an advisory board might provide. 
1. Telephone interviews with Francis McCormick of the General Counsel's office at Atlantic Richfield Corp. and Joseph Russo of the General Counsel's office at the American Petroleum Institute.

2. The term "antitrust laws" is used to indlude: the Sherman Act. 15 U.S.C. $\$ 1$ et seq. ; the Clayton Act, 15 U.S.C. \$12 et seq.; as amended by the Robinson-Patman Act, 15 U.S.C. $\$ \$ 13, \overline{13} \mathrm{a}, 13 \mathrm{~b}$, 2la; the Wilson Tariff Act, 15 U.S.C. SS 8, 9; and the Federal Trade Comission Act, 15 U.S.C. $\$ 41$ et seq.

3. 15 U.S.C. $\$ 1$.

4. 15 U.S.C. $\$ 2$.

5. 15 U.S.C. $\$ 8$.

6. 15 U.S.C. $\$ 15$.

7. 15 U.S.C. $\$ 45(a)(1)$.

8. Id.

9. See J. Von Kalinowski, Antitrust Laws \& Trade Regulation $\$ 9.01$ (2) (b) (Business Organization Series, vol. 16A 1975).

10. United States V. Socony-Vacuum Oil Co., 310 U.S. 150 (1940).

11. Standard Oil Co. v. United States, 221 U.S. 1 (1911).

12. 246 U.S. 231 (1918).

13. Id. at 238 .

14. See Von Kalinowski, Antitrust Laws \& Trade Regulation $\$ 6.02(2)$ (Business Organization Series, vol. 16, 1975).

15. CCH Trade Cases १| 72,907 (C.D. Cal. 1969).

16. United States v. Automobile Manufacturers' Ass'n, 307 F. Supp. 617 , 621 (C.D. Cal. 1969), aff'd per curiam sub. nom. City of New York v. United States, 397 U.S. 248 (1970). 


\section{APPENDIX}

17. Telephone interviews with Francis McCormick of the General Counsel's 1 office at Atlantic Richfield Corp. and Joseph Russo of the General Counsel's office at the American Petroleum Institute.

18. Interstate Circuit, Inc. v. United States, 306 U.S. 208 (1939).

19. Theatre Enterprises, Inc. v. Paramount Film Distributing Corp., 346 U.S. 537, 541 (1954).

20. Federal Trade Commission v. Brown Shoe Co., 384 U.S. 316 (1966).

21. See Handler, "The Inevitability of Risk-Taking," 44 Antitrust L.J. $\overline{377}, 418$ (1.975).

22. See, e.g., S. 2845 , H.R. 11380 (95th Cong., lst Sess.). 


\section{CONCLUSION}

Part of the problem the private sector has had in interacting with the DOE is caused by the policy changes which are inherent in the political process. To a certain extent, these changes are magnified by the lack of adequate private - ntor participation in DOE's RD\&D programs. Obviously,

icies which do not represent the consensus of those who are astected by RD\&D programs are more subject to modification by executive order or legislative mandate than those which do reflect such a consensus. To be sure, there is no reason to expect that a consensus in every aspect of energy RD\&D can be achieved when there is clearly no national agreement on an overall energy strategy. However, it seems certain that such a consensus will not be achieved as long as the private sector is inadequately involved in the planning of DOE's RD\&D activities.

Characteristic of the problem of policy instability is the fact that Congress has occasionally intervened directly into the energy RD\&D field in order to establish new priorities for it. A frequently mentioned example is the Electric \& Hybrid Vehicle Research, Development \& Demonstration Act of $1976 .{ }^{1}$ However, Congress has also been the source of other policy changes, particularly in response to the nation's environmental concerns, which impact dramatically on energy technology implementation.

As may be expected, it is widely believed that DOE's RD\&D program has been characterized by sporadic, unpredictable policy changes, alterations and outright reversals. As a result, there is fear that any product-however large and important-is subject to cancellation or delay at any time by 
the White House, Congress, the federal and state courts, state legislatures and other federal agencies. This fear inhibits private sector cooperation and joint planning, and the instability itself discourages energy investment and punishes initiative and risk taking. ${ }^{2}$

Thus, a self-feeding cycle is created. Inadequate mechanisms for private sector participation in DOE's RD\&D program planning contribute to instabilities in those progras That instability, in turn, contributes to the private sector's hesitation to join DOE's planning processes.

Obviously, shifts in national policy are a necessary part of a democracy and cannot be eliminated merely by an increase in joint planning. However, their effect on the DOE RD\&D effort may be mitigated by long range joint planning. A continuing DOE awareness of all commercialization problems will tend to eliminate programs which are unlikely ever to be implemented. Industry participation appears to be the best way to identify in advance those areas in which business will be hesitant to invest.

The Department of Energy Organization Act $^{3}$ makes repeated reference to the policy objective of promoting private sector participation in energy RD\&D planning. The new Act therefore offers a unique opportunity to lower the procedural barriers and raise the incentives to joint RD\&D planning efforts. However, even with this new legislative mandate, the legal problems discussed in this report will continue to impact on the private sector's willingness and ability to participate in DOE's RD\&D planning activities. 


\section{NOTES}

1. 15 U.S.C. $\$ 2501$ et seq.

2. This view was expressed in interviews with Eric Reich1, President, CoNoco Coal Development Company.

3. P.L. $95-91,42$ U.S.C. $\$ \$ 7101$ et seq. $(8 / 4 / 77)$. 